\title{
OBSERVED BEHAVIOUR OF OLD RAILWAY EMBANKMENTS FORMED OF ASH AND DUMPED CLAY FILL
}

\author{
J.R. Standing ${ }^{1}$, P.R. Vaughan ${ }^{2}$, S. Charles-Jones ${ }^{3}$ and B.T. McGinnity ${ }^{3}$ \\ ${ }^{1}$ Imperial College London, Dept. Civil Engineering \\ 2 formerly Imperial College London, Dept. Civil Engineering (now deceased) \\ 3 formerly London Underground Ltd (now retired)
}

\begin{abstract}
Many old railway embankments were originally formed from loose dumped clay fill on which ash fill was subsequently placed to maintain track level. These have required considerable maintenance, primarily because of embankment movements. They are mostly covered by trees and tree roots are present in both fills. As part of a London Underground Limited programme of stabilisation works in the 1990s, two embankments were instrumented to investigate the mechanisms and causes of movement. Lateral deformations, settlements and pore pressures were measured. This paper describes the instrumentation and monitoring techniques that were adopted and presents the findings from the study. It was found that non-recoverable seasonal movements occur in both the ash fill and the clay fill. The former occur in dry weather, particularly in the slopes of the embankments crests, due to ash particle mobility under train loading when the ash is dry. Clay fill deformations are exacerbated by the presence of tree roots. Movements correlate well with climate, as quantified by the Soil Moisture Deficit determined from meteorological data. Establishing the mechanisms of movement within these ash-clay fill embankments helped guide the design of stabilising measures.
\end{abstract}

KEYWORDS: embankments, field instrumentation, ground movements, monitoring, pore pressures, vegetation. 


\section{INTRODUCTION}

London Underground Limited (LUL) owns some $70 \mathrm{~km}$ of suburban surface track on clay embankments between 2 and $12 \mathrm{~m}$ high. Most were formed by end- and side-tipping clods of London Clay with some hand spreading but no compaction (Skempton, 1995). An example of this process is shown in Figure 1. The natural tipped slopes could be as steep as 1:2, although the open lumpy clay often spread to something flatter without actually forming a slip. Large post-construction movements were characteristic of these embankments of uncompacted fill (Wiseman, 1888). The higher embankments often slipped during construction, in the fill, in clayey alluvium where they crossed small valleys and sometimes in the top of the London Clay foundation usually present. As a consequence of the deformations and slips within these embankments (which could result in slopes as flat as 1:4), they were usually finished and subsequently topped up with steam locomotive ash, used because of its light weight, high shear strength, free-draining nature and ready availability. This locomotive ash typically is vesicular in nature, well graded with particle sizes ranging from fine sand to coarse gravel (roughly $40 \%$ sand to $60 \%$ gravel size by mass), and has an in-situ dry density of about $1 \pm 0.2 \mathrm{t} / \mathrm{m}^{3}$. Crest slopes in ash were as steep as 1:1.5 with up to about $4 \mathrm{~m}$ of ash being placed to maintain track alignment. The London Clay fill material is variable with a mixture of London Clay clods in a softer broken-down clay matrix. 'Best estimate' strength parameters used in the numerical modelling of similar embankments are provided later for reference. Thus these embankments are characterised by steep narrow crests, steep upper slopes in ash and variable clay slopes below (Figure 2). Since about 1960 the slopes have been colonised by shrubs and trees of up to $0.5 \mathrm{~m}$ trunk diameter. Ash has also been employed as an embankment fill material in other parts of the UK besides London and other countries, e.g. the use of ash is detailed in the Malayan Railway Permanent Way Manual, (Way and Works Department, 1952) and the Roorkee Treatise on Civil Engineering, (Brandreth, 1899). More recently hopper ash from power stations has been used rather than 
locomotive ash. Regular maintenance is necessary with both forms of ash crest, involving temporarily lifting the track, adding more stone ballast and ballast tamping to maintain track levels, the whole operation being generally referred to as 'fettling'. Occasional slips have also occurred after abnormally long wet Winter periods, especially at locations where there is little vegetation.

In view of the considerable cost of mitigating the effects of the embankment deformations, LUL instigated a programme of embankment stabilisation works starting from the early 1990s (McGinnity et al., 1998; Perry et al., 1999, O’Brien, 2007). Preliminary investigations involved topographic surveys, historical reviews and consideration of where the greatest maintenance was required. Site investigations were performed at nine major embankment sites (McGinnity and Russell, 1996), representing conditions at most of the LUL embankments where regular track maintenance was necessary. As part of the programme, the Geotechnics Section at Imperial College London (ICL) was employed to instrument two embankments to determine mechanisms of deformation and deterioration. One at High Barnet (Northern Line) to the north of London (grid coordinates E 525716, N 195138) and the other at Roding Valley (Central Line) to the east (E 542309, N 193093). The locations of the two sites are shown in Figure 3. Both are underlain by the London Clay Formation, although at Roding Valley this is overlain by alluvial deposits. The embankments are mainly of London Clay fill topped up with ash. The one at Roding Valley is an unusually high old steam railway embankment which had slipped during construction on clayey alluvium and which consequently had a substantial thickness of ash added to the crest (Anon., 1903). At each embankment location two sections (A and B) were selected for monitoring as presented in Figure 4. Given the method of embankment construction and subsequent compression and consolidation of the fill, the ground profiles are variable but these shown in Figure $\mathbf{4}$ are considered to be representative of the specific sections. Numerous species of trees were present at both sites with a greater density of more mature trees at Roding Valley 
as evident in Figure 5. At High Barnet there were several hawthorn trees ( 3 to $7 \mathrm{~m}$ high) often near the embankment crest with ash, oak, alder and sycamore trees (ranging from 6 to $9 \mathrm{~m}$ in height) further down the slopes. In the vicinity of section B there were less trees and more brambles and wild roses. At Roding Valley there were primarily oak trees (8 to $12 \mathrm{~m}$ high).

Static deformations were measured on the surface of the embankment using conventional surveying techniques and internally within plane sections of the embankments using electrolevel devices installed within instrumentation tubes. In parallel with the displacement measurements, pore water suctions were monitored using tensiometers.

Two principal types of movements were occurring: (i) progressive deformations of the embankments resulting in the need for continuous track bed (ballast) fettling and on some lines the replacement of lineside services and (ii) deep-seated slips which usually occur over a relatively short period of time, put the line out of service and need extensive stabilisation works. ICL were contracted principally to investigate the former, although it was appreciated that there are likely to be connections between the two types of movement. Although this study was completed 25 years ago, the monitoring data, their interpretation and the overall findings have not been published (except in reports to LUL). Together they form two important case studies which guided the design of stabilisation works.

\section{MONITORING TECHNIQUES}

The critical questions posed concerning embankment movement were: what was moving, when, by how much and why? Vertical displacement of the track could be measured by levelling. Lateral movement is a better indicator of instability and it was decided to install flexible plastic tubes in the embankment slopes within which electrolevel devices were installed at specific depths. With ten 
devices in each tube a reasonably good displacement profile could be determined using an array of sub-horizontal, raking (inclined at about $45^{\circ}$ ) and vertical tubes in an embankment section.

\section{Instrumentation tubing and grout selection}

It was important to observe displacements at shallow depth, where the tubes were in potentially deformable loose ash or soft clay. The tube installations had to be flexible enough to deform with the ground. Conventional inclinometer casing was considered to be too stiff, so a medium duty flexible PVC tubing, with a double spiral rigid PVC reinforcement, was adopted (supplied by Griflex Creators Limited, brand name Cre-A-Flex CU hosing). This could bend, extend and contract readily along its length, while the reinforcement prevented radial collapse. It had $76 \mathrm{~mm}$ internal diameter, sufficient for the electrolevels and their carriages, and a $5.8 \mathrm{~mm}$ wall thickness with the inner surface smooth and the outer one ribbed.

Grout was used to fill the annular spaces between the tubes and the ground to provide intimate contact between them. The grout needed to set quite quickly without bleeding but without being too stiff, as otherwise the column of grout formed would affect the compliance of the tube with the ground. Ideally the grout, once set, should have similar properties to the ground in terms of strength and stiffness. A number of trial mixes were investigated experimentally at ICL, after which a grout was adopted with proportions by mass of 1 water : 0.12 Ordinary Portland Cement : 0.28 bentonite. This resulted in an initial water content of $245 \%$ and average unconfined compression strengths (UCS) of $140 \mathrm{kPa}$ and $365 \mathrm{kPa}$ after 7 and 28 days. Subsequent tests on samples taken in the field gave about half these strengths, because the cement was added before the bentonite for practical reasons, rather than the other way round as in the laboratory preparations. A grout UCS value of about $180 \mathrm{kPa}$ was deemed to be broadly compatible with the ash and the clay fill and foundation material strengths 
(suggesting an undrained strength of the clay of about $90 \mathrm{kPa}$ ). Holes were advanced using a rotary drilling rig with a water/foam flush and 100-mm diameter casing (Figure 5). The PVC tubing was then installed, the annular space filled with grout pumped down a tremie pipe and the casing withdrawn.

\section{Electrolevel inclinometers}

Static deformations were measured using 'strings' of electrolevels positioned along the lengths of the tubes. Electrolevels measure rotations by recording changes in resistance across three electrodes partially immersed in an electrolytic fluid as shown in Figure 6a and the output data are converted to angular measurements using calibration factors (see Standing et al., 2001). The devices used were \pm $3^{\text {o }}$ series 0715 electrolevels supplied by Fredericks and calibrated under laboratory conditions to give a resolution of 1 arc second. Each electrolevel was mounted on a carriage of $200 \mathrm{~mm}$ length and held in place within the access tube by a leaf-spring as shown in Figure 6b. Prior to installing the devices within a given tube, one carriage with electrolevel was pushed to the base using a series of rods, taking a reading at each location where an electrolevel was to be installed. In this way the exact orientation of the tube was mapped and each individual electrolevel could be rotated within its housing to be close to the null position once in its appropriate position along the tube, to maximise the range of measurable rotation. The carriages are not connected together in any way. In standard inclinometer tubes there are two pairs of keyways to guide the torpedo or inclinometer device. As the inner surface of the tubes used was smooth, care was taken when pushing the carriages into position to avoid any rod twisting to ensure that measurements were within the correct plane of the embankment. The electrolevel positions within the embankment sections are shown in Figure 4, these were left in place and logged for periods of several months and typically read every three hours. 
In the inclined and horizontal tubes, the carriages remained securely in place with the help of the leafsprings and gravity but in the vertical tubes they are only held by the leaf-springs. Jumps in electrolevel readings within the vertical tube, discussed later, could be attributed to the carriages slipping from vibrations induced from fettling works.

Rotations measured by the electrolevels rotations were integrated along the length of the tube to provide displacements. Relative lateral displacements along each tube (i.e. normal to them) were determined by assuming that each electrolevel measured the change in angle of a straight length between mid-point nodes between them, starting from the deepest device, E1, which was assumed to be fixed in space, as shown schematically in Figure 7. Thus integration of rotations starts from E1, with any rotation registered from E1 being applied to node N1 (a virtual point) midway between E1 and E2, through simple geometry assuming that the chord between E1 and N1 is a straight line (while in reality there is no connection between electrolevels and adjacent nodes). Node N2 is displaced by the equivalent amount as node $\mathrm{N} 1$ but then has the additional displacements added to it from the rotation of E2. The process is repeated along the string, cumulating displacements to the final node position near the top of the tube.

During drilling operations for installing the tubes, a staging on the embankment slopes was necessary to support the drilling rig which could not be sited on or near the crest of the embankment for safety reasons (see Figure 5). Consequently the drill head was always some distance above the slope, it was rotated to give the spread of holes shown on Figure 4. These arrays provided a good spread of observations, which was necessary as there was no prior knowledge of where exactly movement was occurring. In the case of the horizontal and vertical tubes normal displacements result from settlements and horizontal displacements respectively. For the inclined tubes, normal displacements 
are a combination of both and their respective components cannot be isolated. The electrolevel system worked very well, providing clear indications of the deformation patterns within the two embankments.

\section{Surface track surveying}

Early observations at High Barnet from the electrolevel arrays indicated that internal movements were small, while the LUL Track Recording Vehicle (see McGinnity and Russell, 1996) indicated track deterioration and a need for fettling. Track survey levelling was introduced to identify any discrepancy between embankment and track movements. Levels were measured on steel nails in both ends of about 100 sleepers of the southbound track on the instrumented sides of the two embankments, over lengths which included the electrolevel arrays (see plan views in Figure 4). Measurements were taken at the ends of the sleepers rather than on the running rails so that maximum differences would be observed.

A Wild NA28 level and staff with 1-cm divisions were used. Two initial sets of levels were taken on the sleepers at both sites and averages used for base readings. A sleeved pipe grouted into the original ground $4 \mathrm{~m}$ below the embankment foundation was installed as a deep survey datum. The overall accuracy of readings is dictated by factors such as the way the staff is held and weather conditions, but is considered to be within an accuracy of $\pm 1 \mathrm{~mm}$, both from assessing the resulting data and also closing errors were always within $1 \mathrm{~mm}$. The periods of the surveys and the electrolevel observations coincided sufficiently for comparisons to be made. The effect of track fettling was also observed. 


\section{Pore pressure measurements}

Pore pressure measurements using Casagrande standpipes had been made during the original site investigations. In many instances these were dry which is not surprising because of the presence of trees and shrubs on the embankment slopes. To investigate pore water suctions and their seasonal variation and perhaps also to assess the influence of vegetation (especially trees), tensiometers (supplied by Soil Moisture Equipment Corporation, California) were installed. These instruments have a closed standpipe water reservoir system capable of measuring matrix suctions to about $100 \mathrm{kPa}$ (in reality measurements are limited to suctions of about 80 to $90 \mathrm{kPa}$ because of cavitation, Ridley et al., 2003). There are four components: a jet-fill reservoir, a Bourdon vacuum gauge, a length of plastic body tube and a porous ceramic tip. The tip was saturated and the system de-aired prior to installation in a hand-augered hole of about $100 \mathrm{~mm}$ diameter. A smaller diameter purpose-made auger was used to form a recess at the base of the hole into which the ceramic tip could be pushed snugly (see Ridley et al., 1998) and the rest of the hole was backfilled with grout to seal the system. They are designed for installation at shallow depth. At High Barnet six tensiometers were installed at different positions up the bank (Figure 4) with the ceramic tip placed within the clay fill below the ash (at depths from $1.5 \mathrm{~m}$ to $2.7 \mathrm{~m}$ ). Many fine roots were observed in all holes when augering through the ash and the clay.

\section{HIGH BARNET EMBANKMENT CHARACTERISTICS AND BEHAVIOUR}

\section{Electrolevel results}

The positions and numbering of the electrolevels installed in the horizontal, raking and vertical tubes at the High Barnet site are shown in Figure 4. Changes in the raw output data from the devices, converted to rotations, versus time from 16.01.1994 to 11.06.1994 are shown in Figure 8a to $\mathbf{c}$ to assess stability. The figures generally show consistent and monotonic increases in rotation with time. 
It can be seen that there are significant movements near the surface (e.g. electrolevel numbers 9 and 10). The marked reductions in rotation in devices V9 and V10 at 1965 hrs. (7th April 1994 - week 11) and 2980 hrs. (19th May 1994 - week 17) are related to fettling operations at these times, potentially causing the electrolevel carriages to slip as mentioned earlier. There is similar evidence, but with smaller movements, in some of the horizontal tube devices. The decrease in this effect with depth is also consistent with disturbance.

Detailed displacement profiles derived from the electrolevels in the three tubes, plotted on an average weekly basis, are shown in Figure 9a to c where a dual scale is used on both axes. One, at a metre scale using arbitrary coordinates, relates to the spatial position of the nodes between electrolevels (N1 to N10) at the start of the monitoring period (week 0) and the other, at a mm scale, relates to the profiles of nodal displacement along the tubes during subsequent weeks. Each displacement profile plotted in Figure 9a to $\mathbf{c}$ is the average for a given week, the week numbers are marked at the end of each profile in the figures and corresponding dates and any activities taking place at these times are given in Table 1. Because of the resolution and high frequency of readings, the accuracy of the relative displacements are judged to be about $\pm 0.1 \mathrm{~mm}$ over a length of $10 \mathrm{~m}$, evident from the very limited scatter of data at the deeper nodal points of each tube as shown in Figure 9. The real accuracy of the observation depends on the shape of the profile between electrolevels, on the extent to which the rotation of the access tube is typical of the soil and on how well the electrolevel carriages follow the tube. It has been noted from Figure 4b that the vertical and raking tubes extend well into the natural in-situ London Clay foundation, providing a stable fixed datum and it is reasonable to suppose that the deduced displacements are absolute. The horizontal tube is not anchored in this way (its far end is within the London Clay fill) and the movements observed are relative to the inner end, which is beyond the centre of the embankment. However, no significant movements of electrolevels H1 to H5 
were observed. Although in principle this could be consistent with uniform settlement over this length, this is improbable and the deduced horizontal tube movements are also probably absolute.

In all three profiles there is a progressive increase in displacements normal to the tubes, especially in the near vicinity of the embankment slope surface. Also evident in the horizontal and vertical profiles (Figure 9a and c) is the effect of the fettling works which took place during weeks 11 and 17. In both cases this resulted in an apparent reversal of displacements by up to about 2-3 $\mathrm{mm}$. No noticeable reversal is evident for the raking tube (Figure 9b). As the fettling works took place in the vicinity of the track, away from the tops of the tubes, it is not feasible that the operation, which is localised to the track bed, caused an uplift of the ground around the ends of the tubes. The movement is deemed to be apparent and to have resulted from a slight disturbance of the upper electrolevel devices from fettling-induced vibrations. Summary displacement profiles normal to each tube at specific times are shown in Figure 9d, with all three tubes superimposed on the embankment section. In this way the locations of the source of the displacements can be identified and related to the corresponding material (ash or London Clay fill).

The horizontal tube (Figure 9a and d) shows that there is well-defined movement of the outside of the embankment in the ash fill, with vertical displacements of about 4-5 mm over the period of observation. If ground (ash) movement is actually down the slope rather than near vertical, as is likely, the downslope movement giving rise to this settlement would be about 9-12 $\mathrm{mm}$ (taking a slope angle of about $25^{\circ}$ ). Both the raking and the vertical tubes show a dual movement with small displacements occurring over the depth of the clay fill, typically 1 to $2 \mathrm{~mm}$, and markedly larger movements occurring in the outer 1 to $2 \mathrm{~m}$ of the slope. The difference in displacements at the top of the two tubes is significant, the raking and vertical tubes exhibiting about 2.5 and $7.5 \mathrm{~mm}$ normal 
displacement respectively. It appears that the movements are increasing downslope, suggesting that the fill between must therefore be expanding. However, the difference can be explained more realistically by the position of the uppermost electrolevel in each tube, V10 being very near the surface while R10 is about a metre below it. This depth difference has a significant influence on displacements as is evident from the change in magnitude of displacements $1 \mathrm{~m}$ down from the upper node of the horizontal and vertical profiles (Figures 9a and c).

Displacements in the clay fill of the lower slope (below the ash) are most likely promoted by seasonal changes in pore pressure, described in more detail later, with larger movements occurring in the outer more active zone, and smaller ones further within the embankment mass. The movements at depth are likely to be due to tree roots causing pore pressure changes over the full depth of the fill. The measurements indicate that about $70-80 \%$ of the overall near-surface displacements (vertical tube) occurs in the first 10 to 11 weeks (so to early April 1994). A reversal is evident in the week 12 profile, from fettling works on the southbound track, after which displacements continue until the next reversal, also due to fettling works (on the northbound track). The results do not show conclusive evidence of movement decreasing over the period of observation as Winter turned to Summer, as would be consistent with seasonally controlled shrinkage and swelling. However, the magnitude of weekly displacements reduces noticeably after week 5 (late February) and the more reliable observations from the raking hole (where no potential slip of electrolevel carriages was observed) indicate that the deeper movement was slowing down.

\section{Use of soil moisture deficit to quantify climate}

It is well known that plastic clays settle and heave under seasonal climate changes and that the resulting movement is exacerbated by the presence of vegetation, particularly trees. Soil Moisture 
Deficit (SMD), used in the past mainly for agricultural purposes but also more recently for geotechnical appraisals (e.g. Ridley et al., 2004a and b; Smethurst et al., 2006), is calculated from meteorological data as the amount of water which the soil surface can absorb before refusal. It varies with soil type and type of vegetation cover (Biddle, 1983; Driscoll, 1983), as well as with meteorological parameters. SMD was found to be a useful measure to quantify climate for the work described here. High values of SMD imply water loss, increasing suctions and shrinkage/settlement, while low values (at or close to zero) suggest that water is available for swelling and heave. The SMD for London for medium soil and grass cover is shown in Figure 10a for the duration of monitoring at both sites. There is a good correlation between changes in SMD and deformation, expressed here in Figure 10b as normal displacements of node 10, with the effect of any reversals from fettling disturbance removed, resulting in larger maximum displacements than values shown in Figure 9. Generally, displacements develop more rapidly with increasing SMD, although the reasons for this are different at the two sites: the response at High Barnet being controlled primarily by the clay fill while that at Roding Valley results from the considerable thickness of ash, as is discussed in subsequent sections. In the past good correlations have also been observed between embankment slips and prolonged periods of zero SMD (Ridley et al., 2004a \& b).

\section{Observations from the tensiometers at High Barnet}

The tensiometers were observed periodically during 1994 as evident from the data in Figure 10c. The observations follow the seasons, with suctions developing from the end of June (when SMD increases) and starting to decay from mid-October (as SMD reduces). Note that because of a pre-set pressure limit of zero in the instruments in section A, the pore pressures plotted for the first half of 1994 in Figure 10c could have been higher than zero. The pore pressure-SMD trends are typical of the change in the balance between evapo-transpiration / drying and infiltration between Summer and 
Winter conditions. Response to changes is relatively quick, taking one or two weeks, although there is some lag at depth. There is considerable variation between observations, probably associated with the local effects of tree roots. The Winter of 1993/94 was quite wet during December/January (hence SMD values roughly zero and negligible suctions).

General observations elsewhere show that the ash is free draining and does not show significant pore pressures except where water has ponded in it (Ridley et al., 2004a and b; Briggs et al., 2013). At section A greater thicknesses of surface ash are present (compared with section B, see Figure 4), the depth of clay above the tensiometer tips being recorded as $0.75 \mathrm{~m}$ (upper), $0.9 \mathrm{~m}$ (middle) and $0.95 \mathrm{~m}$ (lower). The Summer suctions developed at the upper and middle tensiometers are small (10 - 15 $\mathrm{kPa}$ ) where the ash cover $1.95 \mathrm{~m}$ and $1.6 \mathrm{~m}$ respectively. As the ash is a coarse granular material, suctions within it cannot increase above about $5 \mathrm{kPa}$ regardless of its degree of saturation (evidenced from soil-water retention curves developed by Li and Standing (2014) for sands of similar grain size, assuming that suctions and associated mechanical behaviour of the ash are controlled by its macropore size rather than the micro-pore size of vesicles within individual particles). Consequently suctions cannot be transmitted through the ash body and it acts as a capillary break, preventing drying from the surface. However, in the lower tensiometer (T(A3)) a maximum suction of $50 \mathrm{kPa}$ was recorded. Here the ash cover was $0.65 \mathrm{~m}$, suggesting that this thickness was not sufficient for the ash to act as an effective capillary break. The capillary rise in the ash can be estimated using relationships between this rise and permeability (Vaughan, 1994).

Alternatively, this variable behaviour may reflect different effects of vegetation on the different locations, or the action of the thick ash over the top of the embankment holding a reservoir of water, keeping the upper part of the slope wetter than the lower part. 
The observations at section B show positive Winter pore pressures (Figure 10c). The depth of the tip of each piezometer was $1.5 \mathrm{~m}$ and there was little ash present at the locations where they were installed. The maximum pressure measured at the lower tensiometer is $20 \mathrm{kPa}$, implying some measuring error given the tip depth. However, in general the results are consistent with near hydrostatic Winter pore pressures, suggesting infiltration into a high permeability superficial zone. Such zones would form from shrinkage cracks developing in the predominantly clay fill at this section due to Summer drying, thus markedly increasing permeability (Vaughan, 1994; Dixon et al., 2019). The maximum suction measured in the upper tensiometer (T(B1)) near the top of the embankment slope after the Summer is $50 \mathrm{kPa}$, while in the tensiometer mid-way up the slope it was only $13 \mathrm{kPa}$. These magnitudes are similar to those in profiles observed elsewhere (Vaughan, 1994; Smethurst et al., 2006). The lower tensiometer near the base of the slope shows no suction. This is surprising but a drain that exists at the toe of the slope may have an influence on this response.

The observations show that under Winter conditions, pore pressures at the surface boundary of the clay fill return to zero both where there is no ash fill and beneath ash fill. During Summer conditions, suctions develop in the clay fill in a somewhat random manner, probably due to extensive tree root growth. The roots would also reduce the water content in the ash fill. This in conjunction with drying of the ash material, which in a dry state would have zero suction and hence little strength near its upper surface where effective stresses are very low, would make it very susceptible to near surface down-slope movement under cyclic train loads. 


\section{Track surveys at High Barnet}

Seven surveys of the sleepers were conducted between 14.03.1994 and 31.01.1995 (see Table 1). The instrumented tubes (section B) line up with sleeper number 77 (Figure 4a). The southbound track was fettled on 07.04.1994, one day after the second survey. The changes in level observed for the inner and outer ends of the sleepers on the instrumented (southbound) side of the embankment are presented in Figure 11. During the 23 days prior to fettling the outer nails settled by up to about 5 $\mathrm{mm}$ and the inner nails less. Fettling raised the nails by up to 20 to $25 \mathrm{~mm}$, except over the length from sleepers 45 to 65 , the outer nails being raised more than the inner. Fettling of the northbound track took place on 19.05.1994 and so the displacement profile for the survey of 23.05.1994 shows little difference from the previous survey (18.04.1994).

Settlements from 14.03.1994 to 06.04.1994 added to those measured after 18.04.1994 are shown in Figure 12. Thus changes during the 12-day period between 06.04.1994 and 18.04.1994, when fettling took place, are eliminated (i.e. both uplift from fettling on 07.04.1994 and any subsequent settlement). As mentioned above, there is little development of displacement between 06.04.1994 and 23.05.1994 as fettling of the northbound track took place on 19.05.1994. Most of the settlement occurs between sleepers 70 to 100 after the end of May, coinciding with the onset of Summer conditions and high SMD (see Figure 10a), with a maximum of about $50 \mathrm{~mm}$ developing on the inner ends of the sleepers by the end of November 1994 (Figure 12a). The northbound track on the opposite side to the instrumented section must have been fettled before the next survey on 31.01.1995 as the results from this survey indicate that the inner side of the track had been raised by about $30 \mathrm{~mm}$.

Settlement was generally uneven with most of the surveyed length of the track tilting outwards but at the northern end (sleepers 85 to 100) the tilt was in the opposite sense. The surveys and electrolevel 
observations were concurrent from 14.03.1994 to 11.06.1994 (weeks 8 to 21). Average settlements of the inner and outer ends of five sleepers either side of sleeper 77, in line with the access tubes, were calculated as $1.7 \mathrm{~mm}$ and $7.5 \mathrm{~mm}$ respectively. The movement of the horizontal instrumentation tube, closest to the top of the embankment, was $2.0 \mathrm{~mm}$ which relates to about $5 \mathrm{~mm}$ downslope and of the end of the raking tube was about $1.3 \mathrm{~mm}$. Approximate calculations of the volume of soil movement suggest that about half of the settlement measured at the top of the embankment (by surveying) is accounted for by downslope movement of the ash fill near the crest (from electrolevel monitoring). There is a reasonable reconciliation of the two forms of measurement, bearing in mind (i) that the period over which the crest settlement was monitored included bedding down after fettling and (ii) their relative positions.

\section{RODING VALLEY CHARACTERISTICS AND BEHAVIOUR}

\section{Electrolevel results}

The electrolevels were transferred directly from High Barnet to Roding Valley where observations were made in the same way. The instruments were read continuously over three periods from 12.06.1994 to 24.07.1994 (weeks 1 to 6), 17.08.1994 to 12.10.1994 (weeks 9.5 to 19) and 19.12.1994 to 24.02.1995 (weeks 27 to 36.6, see Table 2). The electrolevels were left in place throughout and readings refer to the same datum. The results obtained are summarised in Figure 13a to c using the same style as with the High Barnet data. Three points should be noted in relation to the calculation of displacements.

(i) Initially when the deformation of the horizontal tube was plotted assuming the far end of the tube (H1) to be fixed, there were upward movements between this point and the centre of the tube (N5) with downward movements beyond the centre and the near (surface) end. The tube is wholly within ash and it is not credible that one side of the embankment goes up while the other side goes down. 
The transition between the two senses of movement occurred roughly at N5 and so displacements were recalculated taking N5 to be the fixed point as shown in Figure 13a. The resulting profiles suggest a hump over the centre of the embankment with no settlement at the fixed point. In reality it would have moved downwards, as evident from the surveying results discussed in the next section, and so total displacement of the tube is underestimated. However, the profiles produced provide instructive and realistic insight into the mechanism of the embankment movements.

(ii) During the period without electrolevel readings between weeks 20 and 26, the reading from electrolevel V5, half way up the vertical tube, jumped and was inconsistent with the trend either side of the electrical shutdown period and with the readings from all the other electrolevels. This is attributed to slippage of the carriage in the vertical tube (similar to the case at High Barnet) and has resulted in distortion of the displacements in this vicinity, but the magnitude is considered to be insignificant and for simplicity, corrections have not been applied.

(iii) A second issue that needed addressing with the displacements calculated for the vertical tube arose from the assumption that its base was fixed. Up to week 27 large downslope movements were registered along the top of the tube where it was in ash. However from week 28, this assumption would lead to an erroneous indication that the ash moved uphill (see Figure 13c), which clearly is not credible. It is apparent that the base of the tube was moving. To address this, two displacement profiles, relating to weeks 33 and 36.6 , have been generated assuming that from week 27 , the point of maximum displacement at node $\mathrm{N} 8$ is fixed. The resulting profiles are far more credible with the lower part of the tube, within the clay fill moving outwards (down slope) during this wet period, as evident from the low SMD values shown in Figure 10a. It is unlikely that the upper part of the tube in the ash did not move down slope as well, implying that displacements at the base are underestimated. Plotted in this way it is apparent that the ash displaced downslope from weeks 1 to 
19, during the dry period with high SMD values, with little movement within the clay fill below. Subsequently, from week 28 , the clay moved out relative to the ash.

The deduced swelling of the clay fill that led to the observed downslope / outward movement of the vertical tube (as interpreted through the corrected profiles of weeks 33 and 36.6 in Figure 13c) affected the results in the horizontal tube in a similar fashion (Figure 13a). However, in this case it is credible that the swelling of clay fill closer to the embankment slopes led to small degrees of heave, the magnitude of which are less than $2 \mathrm{~mm}$ (relative to the assumed fixed point, node N5).

In Figure 10b the normal movement of the tops of the outer ends of the tubes are plotted relative to: (i) node N5 in the case of the horizontal tube; (ii) the inner/lowest end of the raking tube; (iii) the inner end of the vertical tube until week 27, after which the readings are relative to node N8. There is a clear trend, as also evidenced from the High Barnet monitoring data, that greater near surface displacements occur as SMD increases. The results shown in the detailed and summary plots (Figures 13a to d) clearly indicate that the ash fill moves substantially from June to November (Summer and Autumn) while there is a significant SMD. The rate of movement in the ash decreases as SMD reduces and it becomes very small when it becomes zero. Conversely, the clay appears to move by only small amounts and inwards (as evidenced by the displacements observed in the vertical tube below node N5 in Figure 13c) during this period when the ash moved outwards. Similar inward movements of clay fill have been observed within a railway embankment formed of London Clay fill (topped with ash) in Essex (Smethurst et al., 2015). The small backward displacements (maximum of 2 to $3 \mathrm{~mm}$ ) of the lower length of the vertical tube in the London Clay fill at Roding Valley could also, to some degree, result from counter flexure of the tube from the large displacements in the ash above the clay fill. Subsequently, during late Autumn and the Winter, when the SMD reduces to zero, 
the corrected profiles in Figure 13c indicate an outward movement of the clay fill, commensurate with swelling associated with the intake of water.

\section{Track surveys at Roding Valley}

Five level surveys were undertaken to monitor changes in elevation of nails at the ends of 105 consecutive sleepers spanning the length of track with the electolevel tubes using a deep benchmark as reference (see Figure 4d). Dates of the surveys and the two occasions when fettling took place are given in Table 2. Fettling operations took place just before the second survey and in view of this results from survey 1 are of little use. Settlements free of fettling operations can be assessed from surveys 2, 3 and 5 (23.05.1994, 25.07.1994 and 29.11.1994). Changes in level relative to survey 2 are plotted for the subsequent three surveys in Figure 14. Six months after fettling (i.e. 29.11.1994), settlements over most of the surveyed track length have developed by up to about $35 \mathrm{~mm}$. At the west end, close to the electrolevel tubes, the inner rail has settled by up to $10 \mathrm{~mm}$ more than the outer rail. This is in conflict with the deformed shape of the horizontal access tube deep within the ash. It is also evident that the track becomes 'bumpy' on a short wavelength as it settles.

Between sleepers 60 to 80 there were only very small settlements. This length suffered an embankment fire in the past and an attempt was made to extinguish it by grouting. This would have had little benefit in terms of stabilising movements: this was found to be the case from extensive trials and investigations elsewhere (McGinnity et al., 1998). Although no difference in the ash fill was noticed during drilling for section B, it may have been fused sufficiently to suppress movement.

The settlement of sleeper 23, in line with the instrumentation tube array, was about $10 \mathrm{~mm}$ on 25.07.1994 and $20 \mathrm{~mm}$ and $27 \mathrm{~mm}$ on the outer and inner nails respectively on 29.11.1994. The 
movements measured by the electrolevels for these two dates (weeks 6 and 27) at the outer ends of the tubes were about: $6 \mathrm{~mm}$ and $15 \mathrm{~mm}$ for the horizontal tube; $2 \mathrm{~mm}$ and $8 \mathrm{~mm}$ for the raking tube; and $3.5 \mathrm{~mm}$ and $13 \mathrm{~mm}$ for the vertical tube. The movement of the track and the embankment slope are broadly compatible, indicating that deterioration of the track is linked to embankment deformation.

\section{DISCUSSION OF OVERALL MECHANISMS OF MOVEMENT AND STABILISING MEASURES}

The observations have shown that there are significant annual movements in the ash fill in the steep slopes of the embankment crests (see summary Figures 9d and 13d). Most of these movements occur in the Summer and Autumn when the SMD is high and the ash is dry. Numerous tree roots were found within the ash which would dry it out during the Summer. Drying the ash results in a loss of meniscus forces between particles (see schematics shown in Figure 15), making the ash more mobile especially under cyclic loading by trains (c.f. dry sand moving under wheel loading, which does not occur when the same sand is moist). This observation suggests that the track deteriorates faster in the Summer, particularly where the ash is thick.

There are smaller and shallower seasonal movements in the clay fill on the outsides of the slopes where there is no ash fill. However, the observed seasonal movements are not insignificant and are consistent with the movements caused in building foundations in London Clay. They are exacerbated by the effect of tree roots (Marsland et al., 1998; Smethurst et al., 2015). The crest and track settlement is linked to lateral movement of the embankment slopes. When the SMD drops, the clay swells. The upward movement of the horizontal tube ends at Roding Valley from mid-December to February potentially results from this process (Figures 10a and 13a). However, at this location the vertical component of swelling is smaller than the lateral, as evident from the corrected displacement 
profiles in the vertical tube (Figure 13c) where lateral displacements are about five times larger than vertical heave. Net lateral swelling would cause the embankments to spread, leading to an overall downward movement of the crest and track. The lateral swelling displacement is not recovered during shrinkage. Spreading of the embankment is also apparent when the SMD increases, as evident from the results at High Barnet as Summer approached (Figures 9 and 10), despite the fact that inwards shrinkage would be expected. This can be reasoned from consideration of differential shrinkage: the outer clay fill clods would shrink more than the inner wetter fill, resulting in small degrees of potential downwards and outwards rotation (when a clay clod shrinks against the less affected deeper, sloping inner clay fill it moves downwards and outwards as a consequence). A sketch illustrating the mechanism for the high SMD case is shown in Figure 15b. The seasonal cycles of displacements, with little recovery from one to the next, would lead to a progressive spreading of the embankments. Smethurst et al. (2015) observed a steady outward movement of the London Clay fill embankment over a four-year period with larger displacements in the Summer (although this was after trees had been removed from the slopes). Spreading due to these seasonal effects may lead to the development of shear surfaces with lower strength than the surrounding mass (similar to the shear surfaces usually present in soliflucted slopes from historic freeze-thaw processes). Such weakened zones would contribute towards and help explain the occasional slips which occur long after the pore pressure regime should have reached equilibrium.

Vaughan et al., (2004) and Nyambayo et al. (2004) investigated the effect of cyclic seasonal pore pressure changes on embankments, formed of London Clay fill overlain by ash overlying natural London Clay, through numerical analyses. The materials, geometries and dimensions are very similar to those at the two sites described in the paper. Both studies used the same 'best estimate' peak shear strength parameter values of cohesion, $\mathrm{c}^{\prime}$, and angle of internal shearing resistance, $\varphi^{\prime},\left(\right.$ ash $\mathrm{c}^{\prime}$ peak $=2$ 
$\mathrm{kPa}, \varphi_{\text {peak }}^{\prime}=36^{\circ} ;$ London Clay fill $\mathrm{c}_{\text {peak }}^{\prime}=3.4 \mathrm{kPa}, \varphi_{\text {peak }}^{\prime}=22.9^{\circ} ;$ London Clay foundation $\mathrm{c}^{\prime}{ }_{\text {peak }}=7$ $\left.\mathrm{kPa}, \varphi_{\text {peak }}^{\prime}=20^{\circ}\right)$ and accounted for strain softening from peak to residual. These strength values are also very similar to those established by O'Brien et al. (2004) from laboratory testing of block samples retrieved from embankments of London Clay fill. Both sets of numerical analyses indicated that plastic strains progressively increase with cycling, i.e. increasing and decreasing SMD, leading to overall reductions in strength and stability. In both papers plots are presented showing resultant displacement vectors throughout the embankment at different stages, which correlate well with the displacements observed from the electrolevel monitoring (Figures 9 and 13).

The mechanisms referred to above in both the ash and clay fill are expressed schematically in Figure 15 for (a) low and (b) high SMD extremes. The postulated behaviour of the ash correlates well with the observations from the electrolevel data for both seasons. The displacement mechanism for the clay fill is more complex. The swelling of the fill during Winter is well reflected by the field observations. During Summer the electrolevel displacement profiles from High Barnet indicate downward (as shown in Figure 15) but also outward components of movement (Figure 9b and c). A postulated mechanism is sketched in the enlarged view of Figure 15b, as described earlier. Generally the behaviour of the clods within a softer clay matrix is not well understood: the outward movement as SMD increases could be related to differential shrinkage, permeability and degree of saturation between the two elements.

It is important to note that the observations were only made for relatively short durations of about six to eight months, longer durations of several years would ideally be needed to understand fully the complex responses at the two sites which are controlled by different processes and mechanisms. 
Slope movements cause tilt of the track, which may be outward or inward. Inward tilt is likely to be associated with deeper-seated movements in thicker ash fill. Trees and tree roots increase overall stability, but they also increase the severity of seasonal pore pressure changes and the depth which they influence, thus promoting embankment movement. Smethurst et al. (2015) show clearly through the careful field monitoring of an embankment of very similar composition to those discussed here, that the removal of trees decreases crest movements but also the deep-seated suctions which improve embankment stability.

The observations made confirm that treatment of embankment crest slopes should reduce crest settlement and track deterioration (although they are unlikely to eliminate them if the track bed itself is inadequate). The identification of the primary mechanisms of movement within ash and clay fill embankments similar to those presented and discussed in this paper, provided an essential input for the efficient and effective design of structural measures for reducing movements and improving embankment stability. A number of schemes were proposed (McGinnity et al., 1998; O’Brien, 2007), two of which are shown in Figure 16 (although more commonly crest walls with their top supported by a 45 -degree pile raking downward into the embankment were implemented rather than the horizontal tie shown in Figure 16a). It is clear that there is a focus on restraining movements within the ash, the primary culprit leading to the degradation of track alignment.

\section{CONCLUSIONS}

Monitoring both within and at track level of two railway embankments, comprised of uncompacted clay fill with ash placed above subsequently, revealed the primary mechanisms of movement which are strongly controlled by season. During drier periods of the year when SMD is high, the ash becomes mobile and the greatest magnitude of movement occurs at this time. As the track and ballast 
lie directly on the ash, this leads to track level deterioration. Although not intuitive, shrinking of the underlying clay fill also leads to embankment spreading but to a lesser degree. During wetter periods with SMD values close to zero, the ash is more stable but the clay fill swells, again leading to lateral movement within the embankments, especially near the slope surfaces and consequent settlements of the crest and track. The displacements that occur in both periods are mostly irreversible. Very good correlations between SMD, displacements and pore water suctions are evident from the data presented.

Track monitoring using conventional surveying techniques correlated well with the measurements made using electrolevel strings within the body of the embankment and also showed how well the fettling operations worked in maintaining track level. However, the fettling operations are very costly and also if not implemented soon enough, efficient train running could be compromised. Identifying the overall mechanisms of movement contributed to the effective design of structural stabilising measures that have now been implemented along some embankment sections.

The monitoring systems employed in this study worked well and allowed clear patterns of movement to be identified. The data needed careful scrutiny and in cases changes of applied assumptions to produce credible results, but this has been done with confidence. More modern systems, such as shape arrays would allow more accurate and continuous monitoring, especially when combined with monitoring of the tube heads to allow absolute displacements to be determined with confidence.

Further understanding of the overall mechanisms of movement of embankments comprised of complex materials such as ash and clay fill can be achieved using numerical analysis with appropriate modelling capabilities, particularly of root uptake, precipitation and infiltration effects (e.g. 
Nyambayo and Potts, 2010; Briggs et al., 2016). The data presented and discussed in this paper, in particular the internal displacements, would help with the validation and calibration of such analyses.

\section{ACKNOWLEDGEMENTS}

The authors are grateful to London Underground Limited for permission to publish the data. The help and advice from Mr Gerwyn Price concerning the electrolevel systems is also gratefully acknowledged. Thanks too are due to Dr Andrew Ridley for supplying specific information on the ash material and to Mr Mike Chrimes for help in sourcing historic literature relating to the use of ash in embankments. The profile shown in Figure $\mathbf{3}$ is reproduced from drawings compiled by Mott MacDonald.

\section{REFERENCES}

Anon. (1903). The expansion of the Great Western Railway. Railway Magazine, Vol. XII, June, pp. $479-482$.

Biddle, P.G. (1983). Patterns of soil drying and moisture deficit in the vicinity of trees on clay soils. Géotechnique, Vol. 33, No. 2, pp 107-126.

Brandreth, A.M. (1899). Roorkee Treatise on Civil Engineering, Vol. II, Section IX, Railways. $7^{\text {th }}$ Edition (revised by A.M. Brandreth), Printed by Thomason Civil Engineering Press.

Briggs, K. M., Smethurst, J. A., Powrie, W. and O'Brien, A. S. (2013). Wet winter pore pressures in railway embankments. Proceedings of the Institution of Civil Engineers - Geotechnical Engineering, Vol. 166, No. GE5, pp 451-465.

Briggs, K.M., Smethurst, J.A., Powrie, W. and O'Brien, A.S. (2016). The influence of tree root water uptake on the long term hydrology of a clay fill railway embankment. Transportation Geotechnics, Vol. 9, pp 31-48. 
Dixon, N., Crosby, C.J., Stirling, R., Hughes, P.N., Smethurst, J.A., Briggs, K., Hughes, D., Gunn, D., Hobbs, P., Loveridge, F., Glendinning, S., Dijkstra, T. and Hudson, A. (2019). In situ measurements of near-surface hydraulic conductivity in engineered clay slopes. Quarterly Journal of Engineering Geology and Hydrogeology, Vol. 52, No. 2, pp 123-135.

Driscoll, R. (1983). The influence of vegetation on the swelling and shrinking of clay soils in Britain. Géotechnique, Vol. 33, No. 2, pp 93-105.

Li, Q. and Standing, J.R. (2014). Experimental set-up for determining Soil Water Retention Curves for granular soils during drying. Acta Geologica Sinica, Vol. 88, No. 6, pp 1875 - 1883.

Marsland, F., Ridley, A.M., Vaughan, P.R. and McGinnity, B.M. (1998). Vegetation and its influence on the soil suction in clay slopes. Proc. 2nd Int. Conf. Unsaturated Soils, Beijing. International Academic Publishers, Vol. 1, pp 249-254.

McGinnity, B.T., Fitch, T. and Rankin, W.J. (1998). A systematic and cost-effective approach to inspecting, prioritising and upgrading London Underground's earth structures. Proc. Seminar on The value of geotechnics in construction. Emap Construct, Construction Research communications Ltd, pp 309-321.

McGinnity, B.T. and Russell, D. (1996). Investigation of London Underground earth structures. Proc. Int. Conf. on Advances in Site Investigation Practice, London, Craig C. (ed.), Thomas Telford, pp 230-242.

Nyambayo, V. P., Potts, D. M. and Addenbrooke, T. I. (2004). The influence of permeability on the stability of embankments experiencing seasonal cyclic pore water pressure changes. Proc. Int. Conf. On Advances in Geotechnical Engineering, The Skempton Conference, Jardine R.J., Potts D.M. and Higgins K.G. (eds). Thomas Telford, London, Vol. 2, pp. 898-910.

Nyambayo, V.P. and Potts, D.M. (2010). Numerical simulation of evapotranspiration using a root water uptake model. Computers and Geotechnics, Vol. 37, pp 175-86. 
O’Brien, A.S. (2007). Rehabilitation of urban railway - investigation, analysis, and stabilisation. In Proceedings of the $14^{\text {th }}$ European conference on soil mechanics and geotechnical engineering, Madrid (eds V. Cuellar, E. Dapena, E. Alonso, J. M. Echave, A. Gens, L. J. de Justo, C. Oteo, J. M. Rodriguez-Ortiz, C. Sagaseta, P. Sola and A. Soriano), vol. 1, pp. 125-143. Rotterdam, the Netherlands: Millpress.

O’Brien, A.S., Ellis, E.A. and Russell, D. (2004). Old railway embankment clay fill - laboratory experiments, numerical modelling and field behaviour. Proc. Int. Conf. On Advances in Geotechnical Engineering, The Skempton Conference, Jardine R.J., Potts D.M. and Higgins K.G. (eds). Thomas Telford, London, Vol. 2, pp. 911-921.

Perry, J., McGinnity, B.T. and Russell, D. (1999). Railway earth structures: their condition, management and influence of track quality. Keynote paper, Proc. Railway Engineering 99. CD Rom ISBN 0-0947644-39-3. Engineering Technical Press, Edinburgh.

Ridley, A.M., Dineen, K., Burland, J.B. and Vaughan, P.R. (2003). Soil matrix suction: some examples of its measurement and application in geotechnical engineering. Géotechnique, Vol. 53, No. 2, pp 241-253.

Ridley, A.M., Marsland, F., and Patel, A. (1998). Tensiometers - their design and use for civil engineering purposes. Geotechnical Site Characterisation: Proc. 1st International Conference on Site Characterisation, Atlanta, USA, P.K.Robertson \& P.W.Mayne (eds.). Balkema, Vol. 2, pp 851-856. Ridley, A.M., McGinnity, B.T. and Vaughan, P.R. (2004a). Role of pore pressures in embankment stability. Proc. ICE Geot. Engng., Vol. 157, No. GE4, pp 193-198.

Ridley, A.M., Vaughan, P.R., McGinnity, B.T. and Brady, K. (2004b). Pore pressure measurements in infrastructure embankments. Proc. Int. Conf. On Advances in Geotechnical Engineering, The Skempton Conference, Jardine R.J., Potts D.M. and Higgins K.G. (eds). Thomas Telford, London, Vol. 2, pp 923 - 932. 
Skempton, A.W. (1995). Embankments and cuttings on the early railways. Construction History, Vol. 11, pp 33-49.

Smethurst, J.A., Clarke, D. and Powrie, W. (2006). Seasonal changes in pore water pressure in a grass-covered cut slope in London Clay. Géotechnique, Vol. 56, No. 8, pp 523-537.

Smethurst, J.A., Briggs, K.M., Powrie, W., Ridley, A.M. and Butcher, D.J.E. (2015). Mechanical and hydrological impacts of tree removal on a clay fill railway embankment. Géotechnique, Vol. 65, No. 11, pp 869-882.

Standing, J.R., Withers, A.D. and Nyren, R.J. (2001). Measuring techniques and their accuracy. Building response to tunnelling. Case studies from the Jubilee Line Extension, London, Volume 1, Projects and methods, Burland J.B., Standing J.R. and Jardine F.M. (eds). CIRIA Special Publication 200. CIRIA and Thomas Telford, pp 273-299.

Vaughan, P.R. (1994). "Assumption, prediction and reality in geotechnical engineering".

Géotechnique, Vol. 44, No. 4, pp 573-609.

Vaughan, P.R., Kovacevic, N. and Potts, D. M. (2004). Then and now: some comments on the design and analysis of slopes and embankments. Proc. Int. Conf. On Advances in Geotechnical Engineering, The Skempton Conference, Jardine R.J., Potts D.M. and Higgins K.G. (eds). Thomas Telford, London, Vol. 3, pp. 15-64.

Way and Works Department (1952). Malayan Railway - Permanent Way Manual (3 ${ }^{\text {rd }}$ Ed.), Chapter 1 Formation, Cess, Drainage and Ballast. The Art Printing Works.

Wiseman, W. (1888). Railway embankments. The Railway Engineer, Vol. IX, No. 11 (Nov.), pp 343-350. 
Table 1. Week numbers relating to High Barnet and corresponding dates.

\begin{tabular}{|c|c|c|}
\hline Week number & Date & Comments \\
\hline 0 & 16.01 .1994 & Electrolevels installed \\
\hline 1 & 23.01 .1994 & \\
\hline 2 & 30.01 .1994 & \\
\hline 3 & 06.02 .1994 & \\
\hline 4 & 13.02 .1994 & \\
\hline 5 & 20.02 .1994 & \\
\hline 6 & 27.02 .1994 & \\
\hline 7 & 06.03 .1994 & \\
\hline 8 & 13.03 .1994 & Track survey 1 (14.03.1994) \\
\hline 9 & 20.03 .1994 & \\
\hline 10 & 27.03 .1994 & \\
\hline 11 & 03.04 .1994 & $\begin{array}{l}\text { Track survey } 2(06.04 .1994) \\
\text { Fettling on 07.04.1994 (SB) }\end{array}$ \\
\hline 12 & 10.04 .1994 & \\
\hline 13 & 17.04 .1994 & Track survey 3 (18.04.1994) \\
\hline 14 & 24.04 .1994 & \\
\hline 15 & 02.05 .1994 & \\
\hline 16 & 09.05 .1994 & \\
\hline 17 & 15.05 .1994 & Fettling on 19.05.1994 (NB) \\
\hline 18 & 22.05 .1994 & Track survey 4 (23.05.1994) \\
\hline 19 & 29.05 .1994 & \\
\hline 20 & 06.06 .1994 & \\
\hline 21 & 11.06 .1994 & Electrolevels removed \\
\hline- & 09.08 .1994 & Track survey 5 \\
\hline- & 29.11 .1994 & Track survey 6 \\
\hline- & 31.01 .1995 & Track survey 7 \\
\hline
\end{tabular}


Table 2. Week numbers relating to Roding Valley and corresponding dates.

\begin{tabular}{|c|c|c|}
\hline Week number & Date & Comments \\
\hline- & 29.03.1994 & Track survey 1 \\
\hline- & $15-22.05,1994$ & Fettling (exact date unknown) \\
\hline- & 23.05 .1994 & Track survey 2 \\
\hline 0 & 12.06.1995 & Electrolevels installed \\
\hline 1 & 19.06.1994 & \\
\hline 2 & 26.06 .1994 & \\
\hline 3 & 07.07 .1994 & \\
\hline 4 & 10.07 .1994 & \\
\hline 5 & 17.07.1994 & \\
\hline 6 & 24.07.1994 & $\begin{array}{l}\text { Logger stopped } 24.07 .1994 \\
\text { Track survey } 3(25.07 .1994)\end{array}$ \\
\hline 7 & 31.07 .1994 & No readings \\
\hline 8 & 07.08 .1994 & No readings \\
\hline 9 & 14.08 .1994 & Logger restarted 17.08.1994 \\
\hline 10 & 21.08 .1994 & \\
\hline 11 & 28.08.1994 & \\
\hline 12 & 04.09 .1994 & \\
\hline 13 & 11.09 .1994 & \\
\hline 14 & 18.09.1994 & \\
\hline 15 & 25.09 .1994 & \\
\hline 16 & 02.10 .1994 & \\
\hline 17 & 09.10 .1994 & \\
\hline 18 & 16.10 .1994 & \\
\hline 19 & 23.10 .1994 & Logger stopped 23.10.1994 \\
\hline 20 & 30.10 .1994 & No readings \\
\hline 21 & 06.11 .1994 & No readings \\
\hline 22 & 13.11.1994 & No readings \\
\hline 23 & 20.11 .1994 & No readings \\
\hline 24 & 27.11 .1994 & Track survey 4 (29.11.1994) \\
\hline 25 & 04.12 .1994 & No readings \\
\hline 26 & 11.12.1994 & No readings \\
\hline 27 & 18.12 .1994 & Logger restarted 19.12.1994 \\
\hline 28 & 25.12.1994 & \\
\hline 29 & 01.01 .1995 & \\
\hline 30 & 08.01 .1995 & \\
\hline 31 & 15.01 .1995 & Fettling (14-16.01.1995) \\
\hline 32 & 22.01 .1995 & \\
\hline 33 & 29.01 .1995 & Track survey 5 (30.01.1995) \\
\hline 34 & 05.02 .1995 & \\
\hline 35 & 12.02 .1995 & \\
\hline 36 & 19.02 .1995 & \\
\hline 36.6 & 24.02 .1994 & Electrolevels removed \\
\hline
\end{tabular}


List of Figures

Figure 1. Formation of embankments from London Clay fill by side-tipping from railway carriages (photograph courtesy of the Transport Museum: site of Hendon Central Underground station, Northern line by Topical Press, 03/10/1922).

Figure 2. Typical ash embankment profile.

Figure 3. Location of the two monitored sites. (C) Crown copyright/database right 2012: an Ordnance Survey/EDINA supplied service).

Figure 4. Details of embankments and instrumentation layouts: (a), (b), (c) plan and instrumented sections A and B at High Barnet; (d) and (e) plan and instrumented section at Roding Valley.

Figure 5. Drilling the raking hole at section A, Roding Valley (07.12.1993).

Figure 6. Schematic details of the electrolevel devices: (a) operating principle; (b) carriage on which the devices were mounted, shown in horizontal position (within inclinometer tube on left).

Figure 7. Sketch showing assumptions and methodology used in determining displacements from electrolevel rotations.

Figure 8. Continuous electrolevel data (converted from voltage to rotations) from (a) horizontal, (b) raking and (c) vertical tubes for the monitoring duration at High Barnet.

Figure 9. Processed electrolevel data from High Barnet expressed with dual scale for: (a) horizontal tube; (b) raking tube; (c) vertical tube; and (d) summary plot. Note that values at ends of each profiles relate to week numbers.

Figure 10. Relation of displacements and pore water pressures with SMD plotted against entire duration of monitoring at High Barnet and Roding Valley: (a) SMD; (b) progressive development of displacement of upper most electrolevel tubes (with effects of fettling removed; and (c) pore water pressures from tensiometers at High Barnet.

Figure 11. Results from track level surveying at High Barnet: changes in vertical displacement along length of track surveyed.

Figure 12. Track levelling survey data: cumulative settlements (with fettling effects removed) over a ten-month period at High Barnet: (a) inner; (b) outer sleeper ends.

Figure 13. Processed electrolevel data from Roding Valley expressed on dual scale for: (a) horizontal tube; (b) raking tube; (c) vertical tube; and (d) summary plot. Note that values at ends of each profiles relate to week numbers.

Figure 14. Track levelling survey data: cumulative settlements over an eight-month period at Roding Valley.

Figure 15. Schematics showing mechanisms of seasonal embankment fill movements for: (a) Winter; and (b) Summer conditions.

Figure 16. Stabilisation methods for the ash/clay fill embankments: (a) tied bored mini pile walls; (b) mixed-in-place (MIP) logs and lime piles (from McGinnity et al., 1998). 


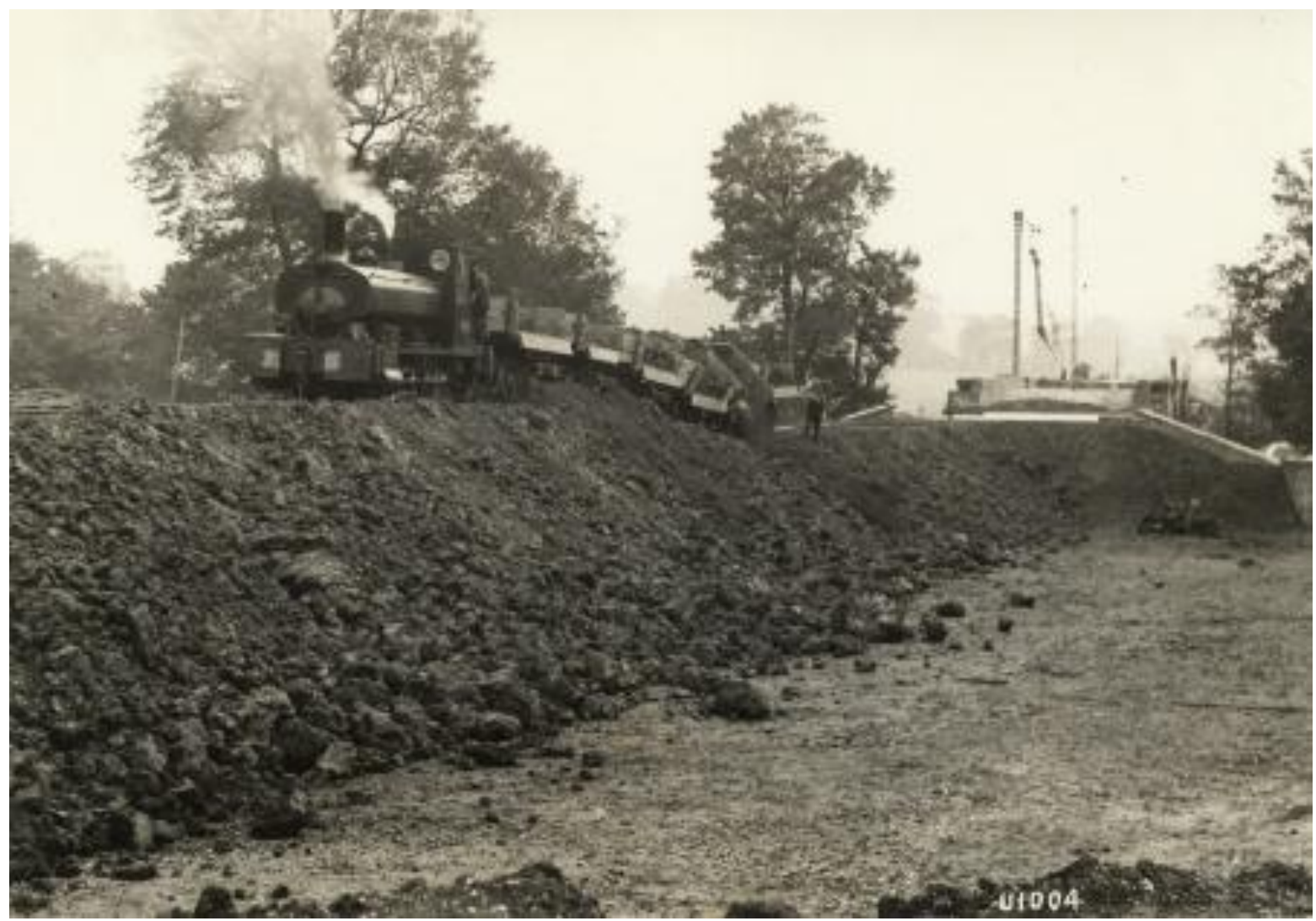

Figure 1. Formation of embankments from London Clay fill by side-tipping from railway carriages (photograph courtesy of the Transport Museum: site of Hendon Central Underground station, Northern line by Topical Press, 03/10/1922). 


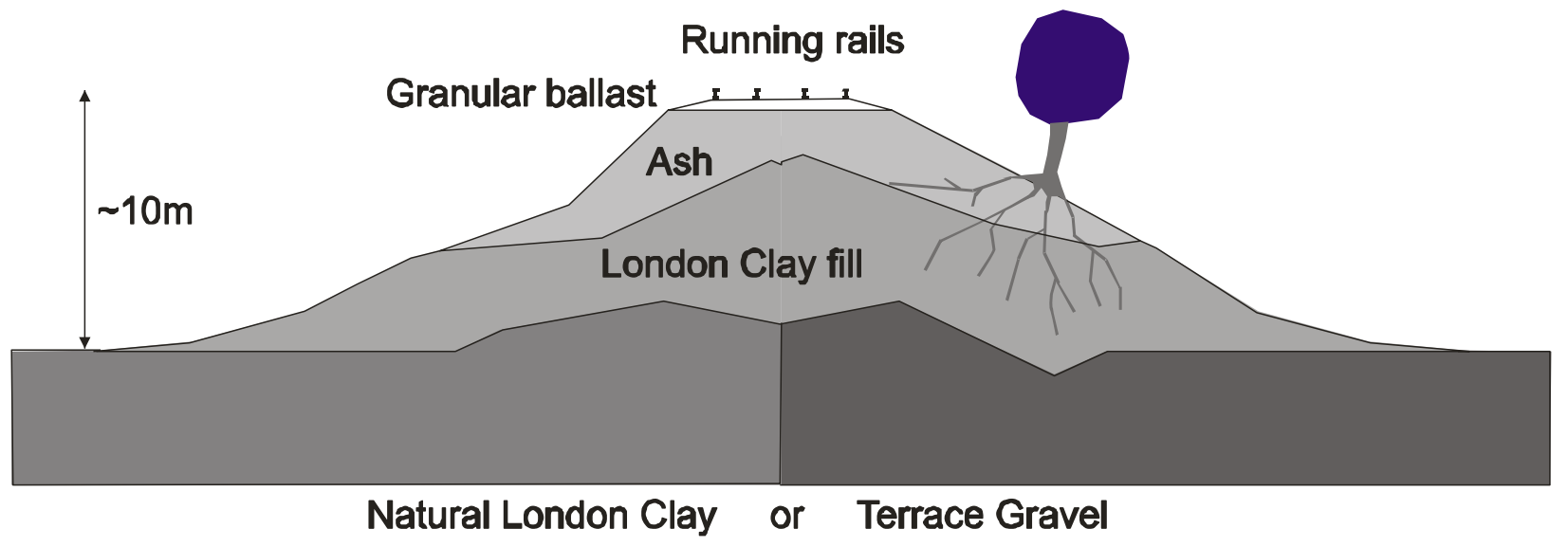

Figure 2. Typical ash embankment profile. 


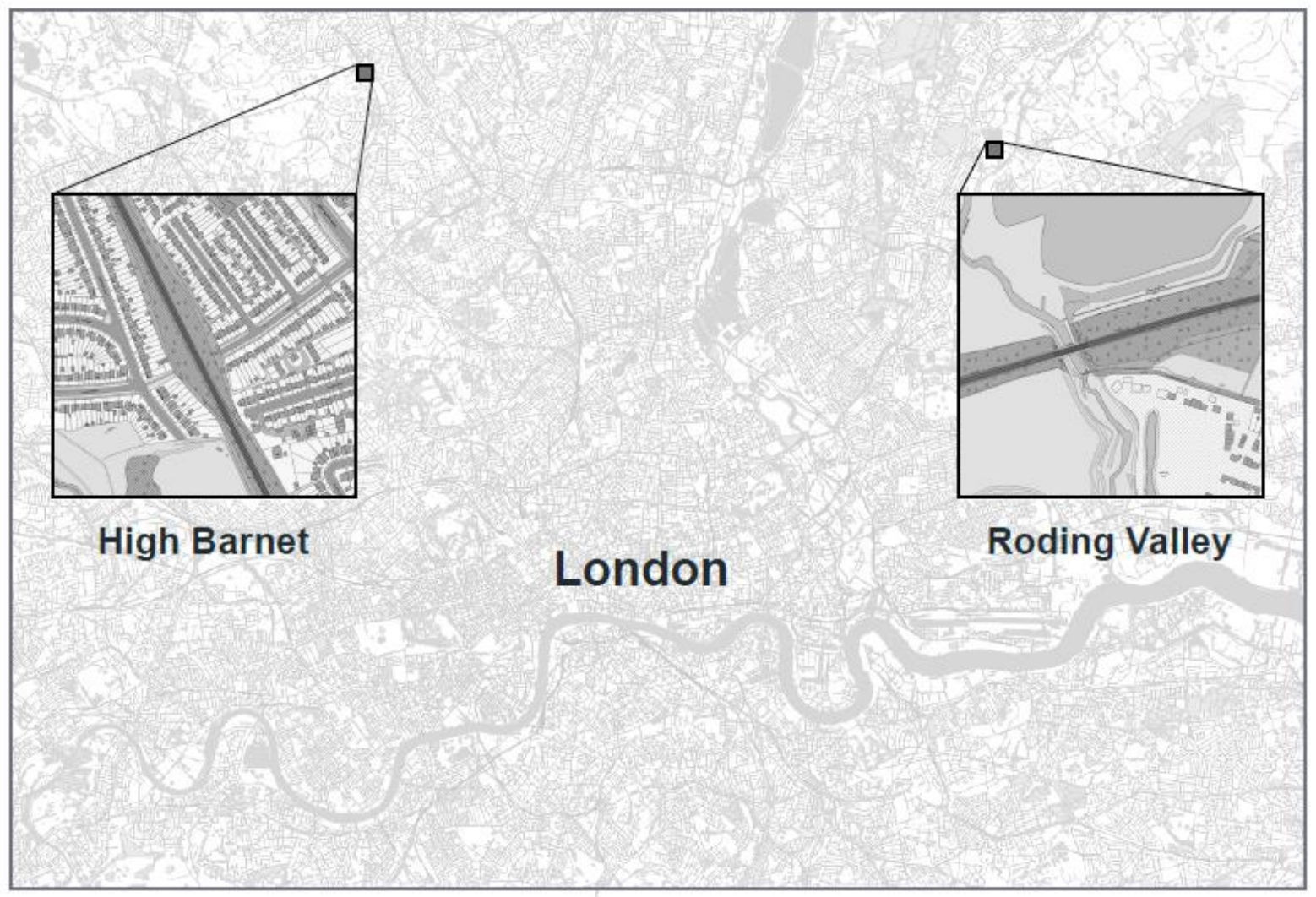

Figure 3. Location of the two monitored sites. (C) Crown copyright/database right 2019: an Ordnance Survey/EDINA supplied service). 
(a)

\begin{tabular}{|c|c|c|c|}
\hline & Section B & Section A & \\
\hline & $+\mathrm{T}(\mathrm{B} 3)$ & & \\
\hline & $\underset{R+}{D+}+\underset{R}{V+}+(B 2)$ & $\begin{array}{l}T(A 3)+++R \\
T(A 2)++H\end{array}$ & $\begin{array}{l}\text { Access (electrolevel) } \\
\text { tubes (not used) }\end{array}$ \\
\hline & $\mathrm{H}+\quad+\mathrm{T}(\mathrm{B} 1)$ & $T(A 1)+$ & \\
\hline
\end{tabular}

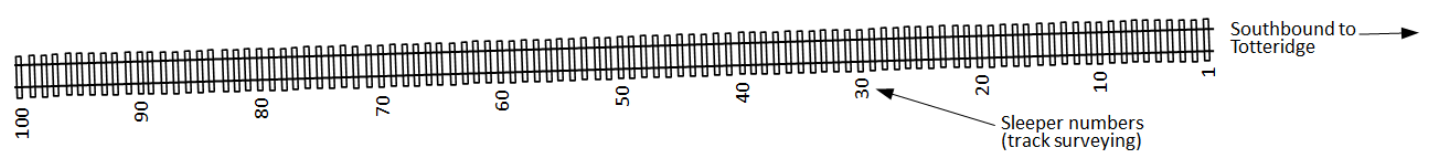

$$
\begin{array}{ll}
\text { Key } \quad \text { D-datum (for surveying) } \\
\mathrm{H} \text { - position of top of horizontal tube } \\
\mathrm{R}-\text { position of top of raking tube } \\
\mathrm{V} \text { - position of top of vertical tube } \\
\mathrm{T}-\text { teniometer }
\end{array}
$$

(b)

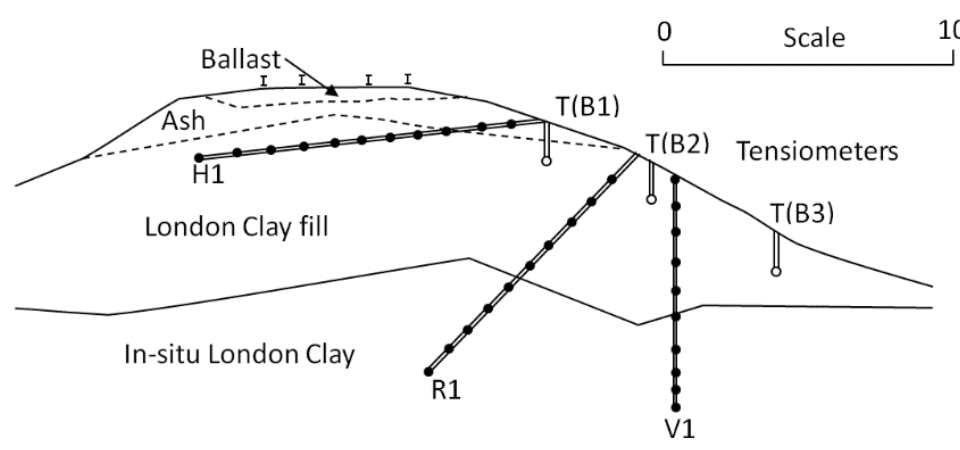

(c)

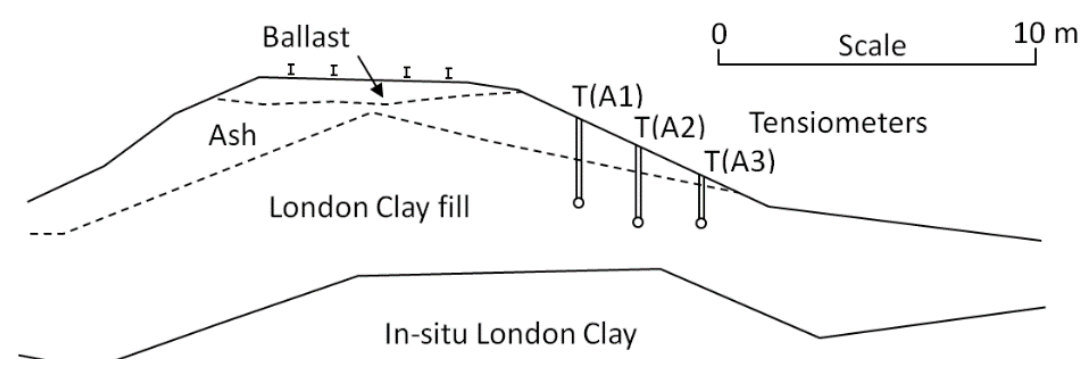

(d)

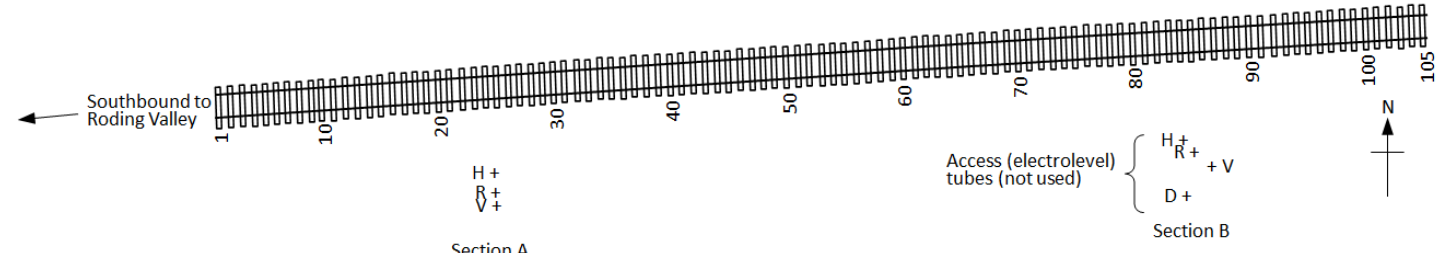

(e)

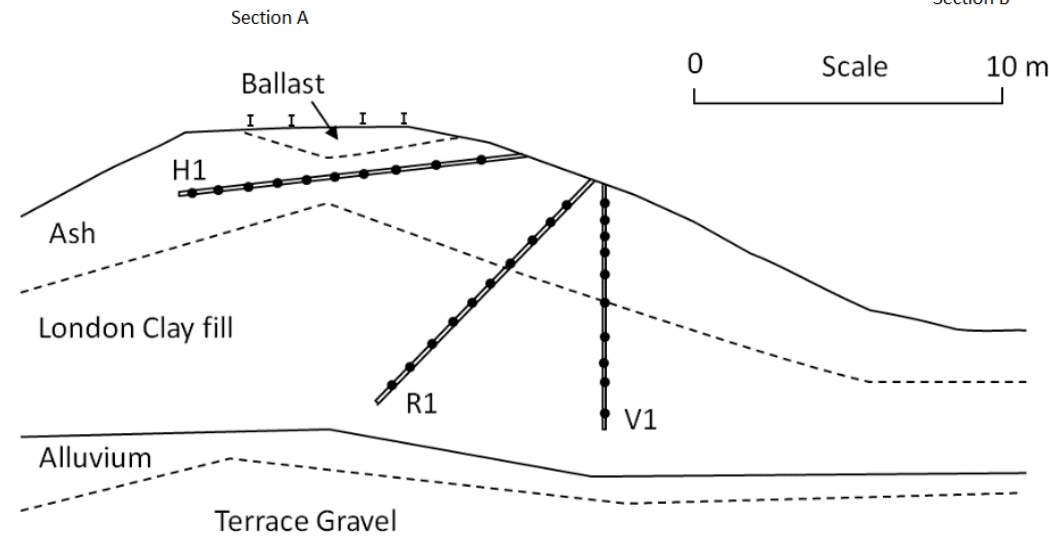

Figure 4. Details of embankments and instrumentation layouts: (a), (b), (c) plan and instrumented sections A and B at High Barnet; (d) and (e) plan and instrumented section at Roding Valley. 


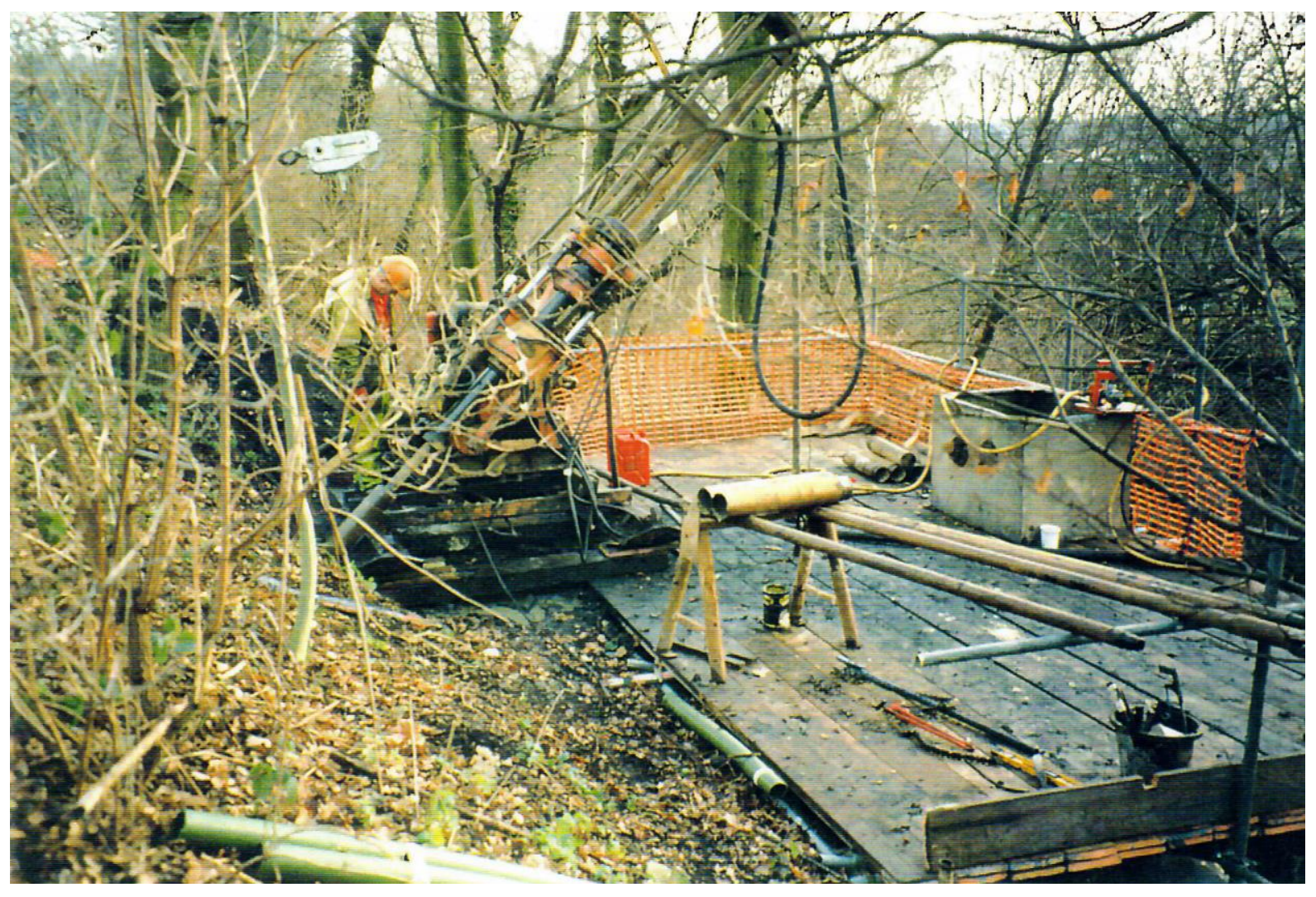

Figure 5. Drilling the raking hole at section A, Roding Valley (07.12.1993). 


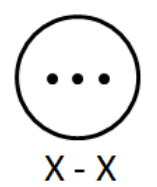

(a)

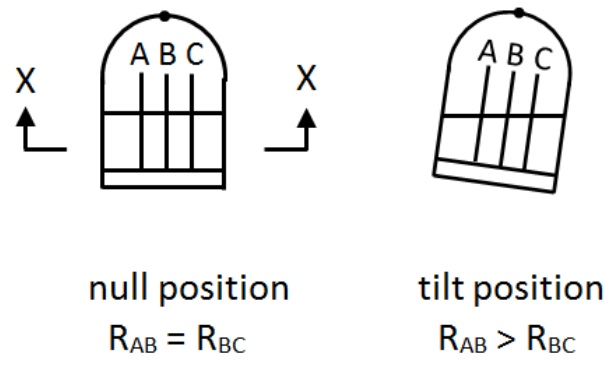

(b)

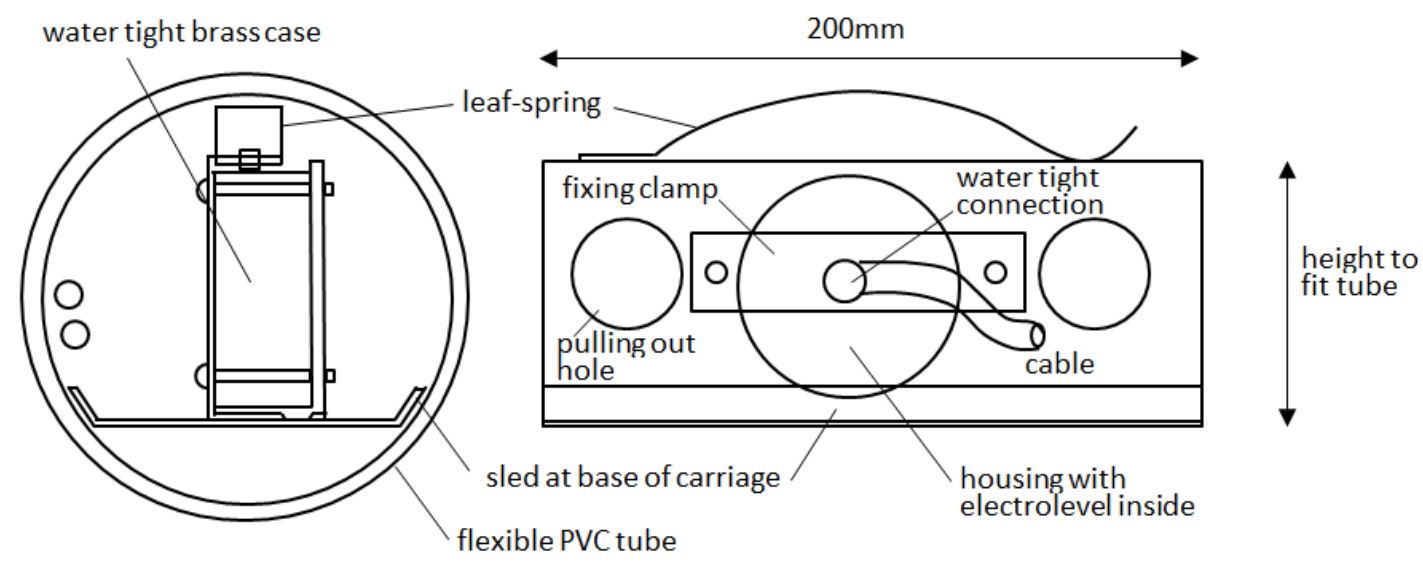

Figure 6. Schematic details of the electrolevel devices: (a) operating principle; (b) carriage on which the devices were mounted, shown in horizontal position (within inclinometer tube on left). 
$+\quad$ Electrolevel position

- Node position

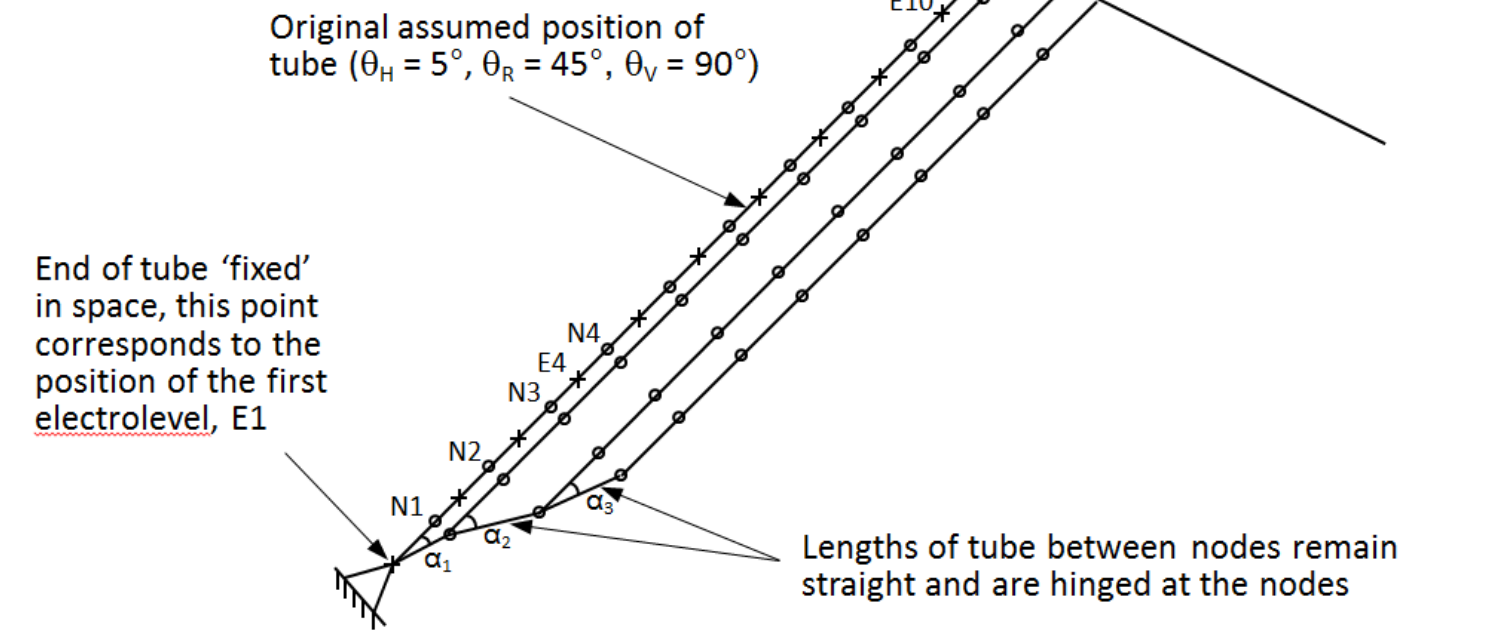

Figure 7. Sketch showing assumptions and methodology used in determining displacements from electrolevel rotations. 

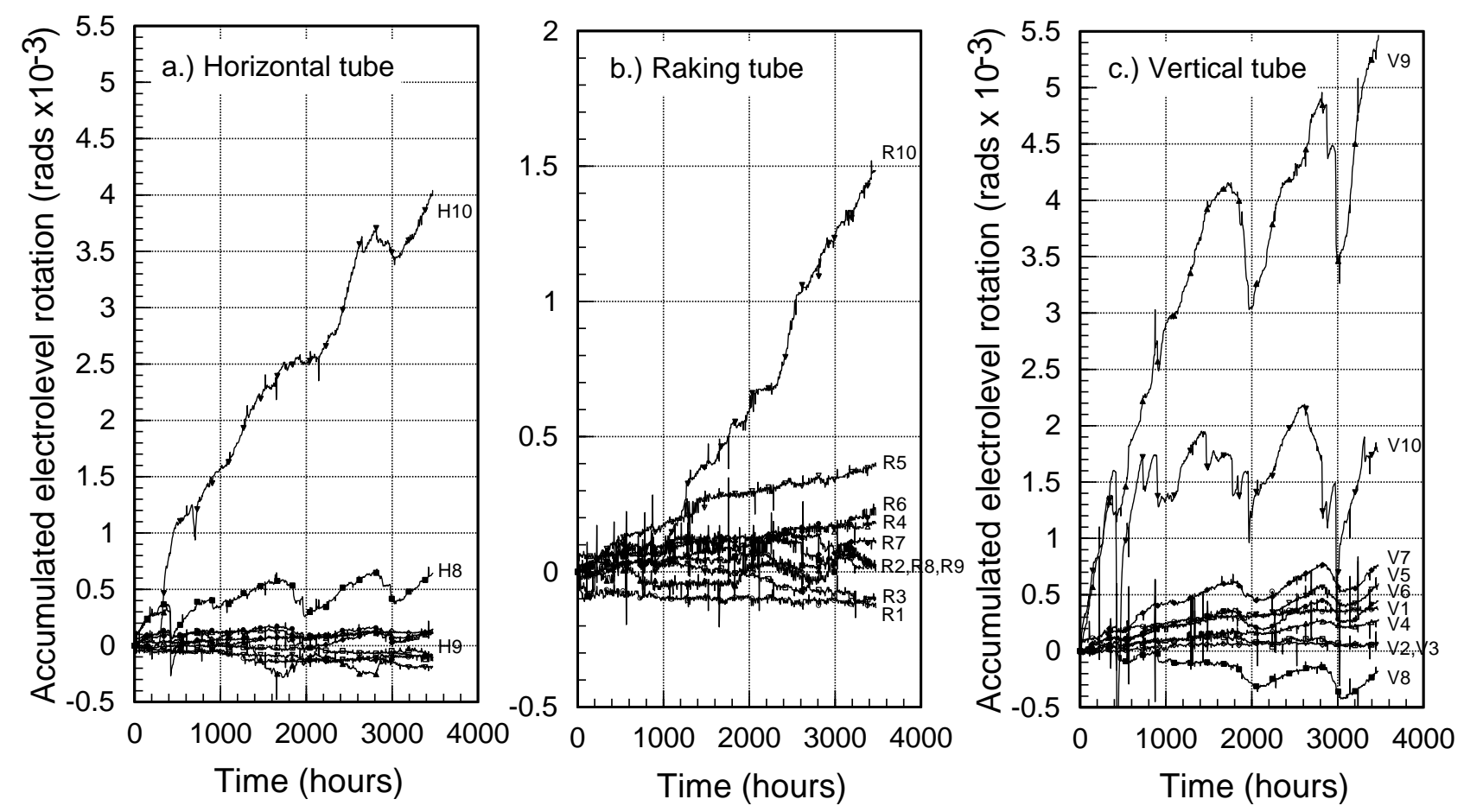

Figure 8. Continuous electrolevel data (converted from voltage to rotations) from (a) horizontal, (b) raking and (c) vertical tubes for the monitoring duration at High Barnet. 


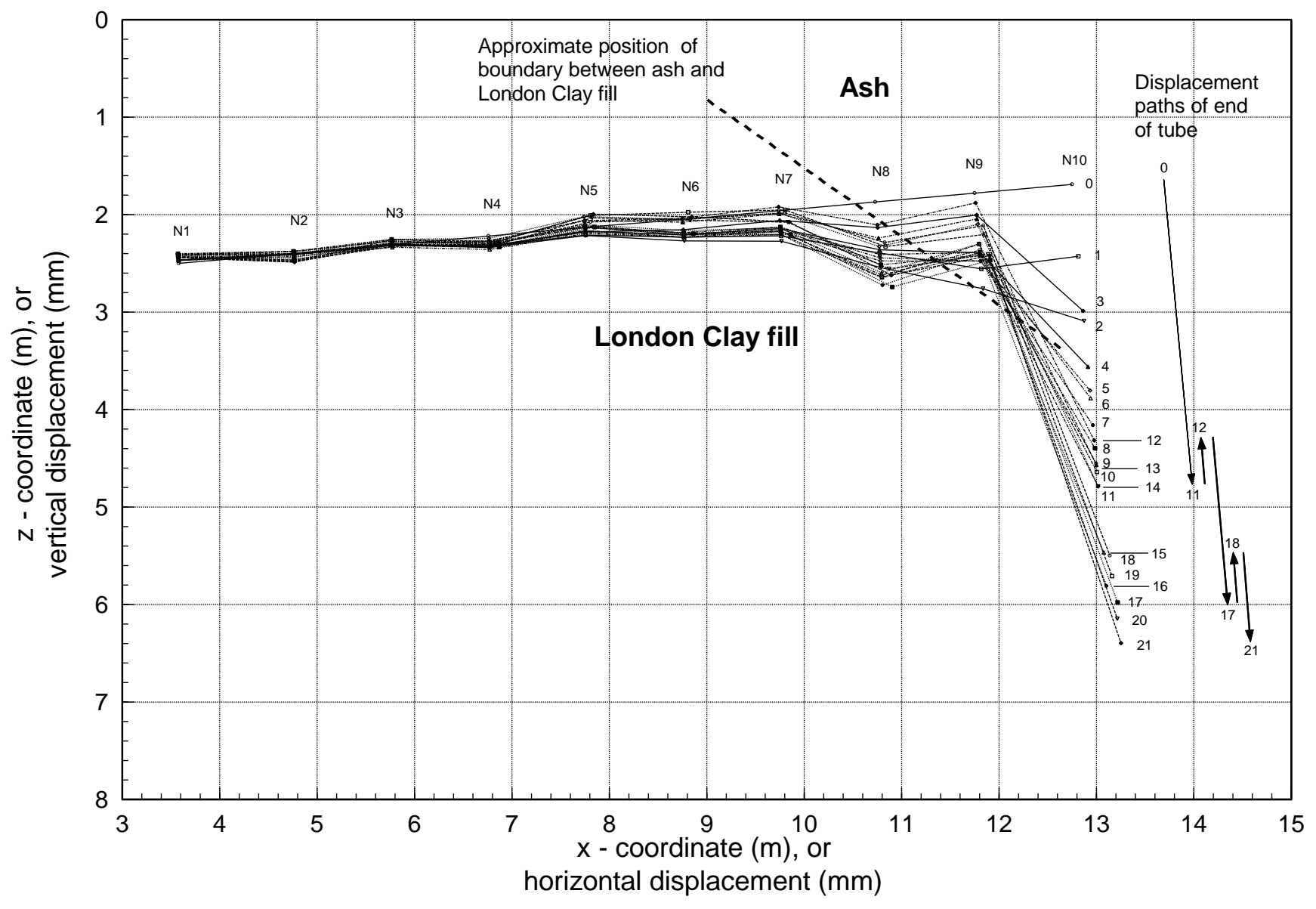

(a)

Figure 9. Processed electrolevel data from High Barnet expressed with dual scale for: (a) horizontal tube (with inset sketch showing assumptions and methodology used in determining displacements from electrolevel rotations); (b) raking tube; (c) vertical tube; and (d) summary plot. Note that values at ends of each profiles relate to week numbers. 


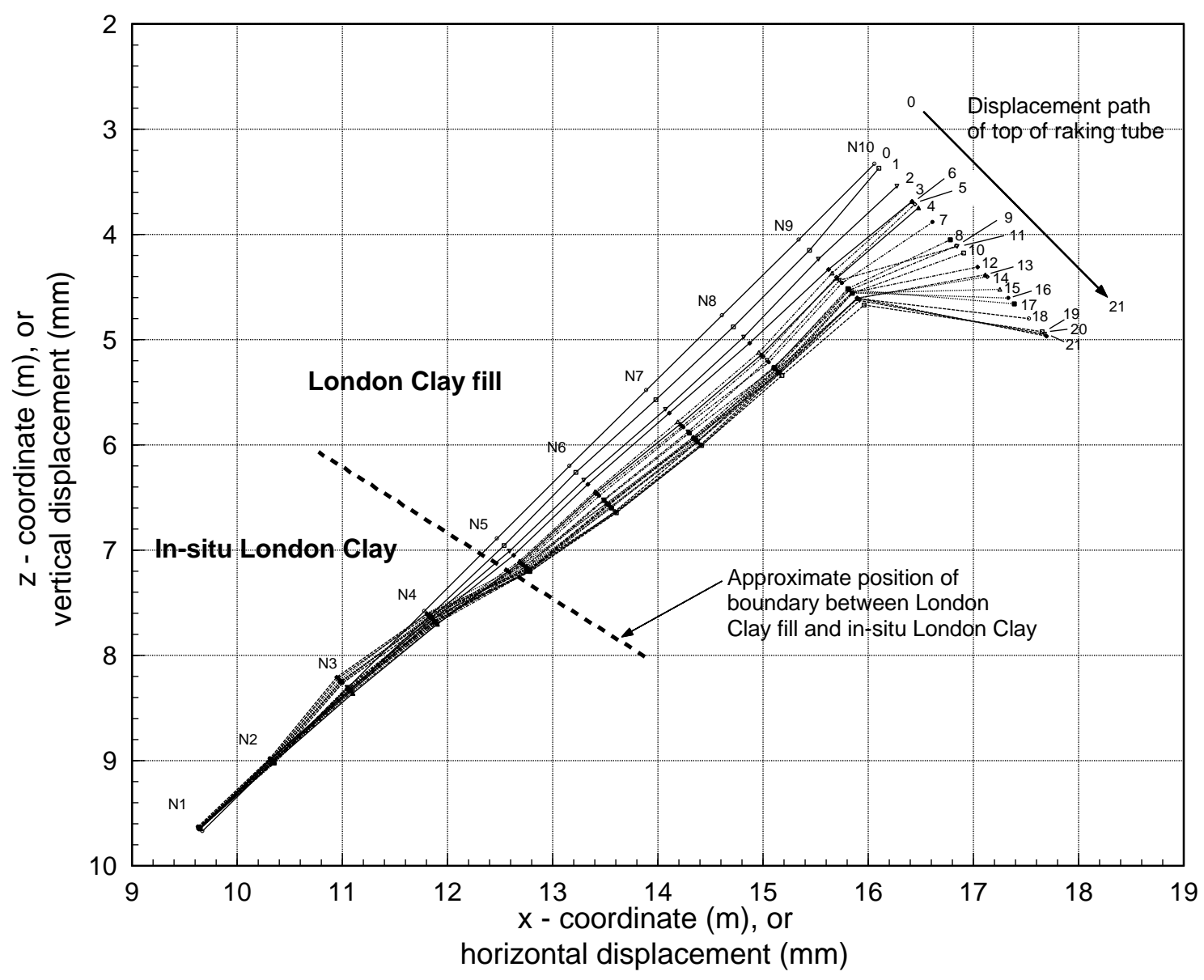

(b)

Figure 9. Processed electrolevel data from High Barnet expressed with dual scale for: (a) horizontal tube; (b) raking tube; (c) vertical tube; and (d) summary plot. Note that values at ends of each profiles relate to week numbers. 


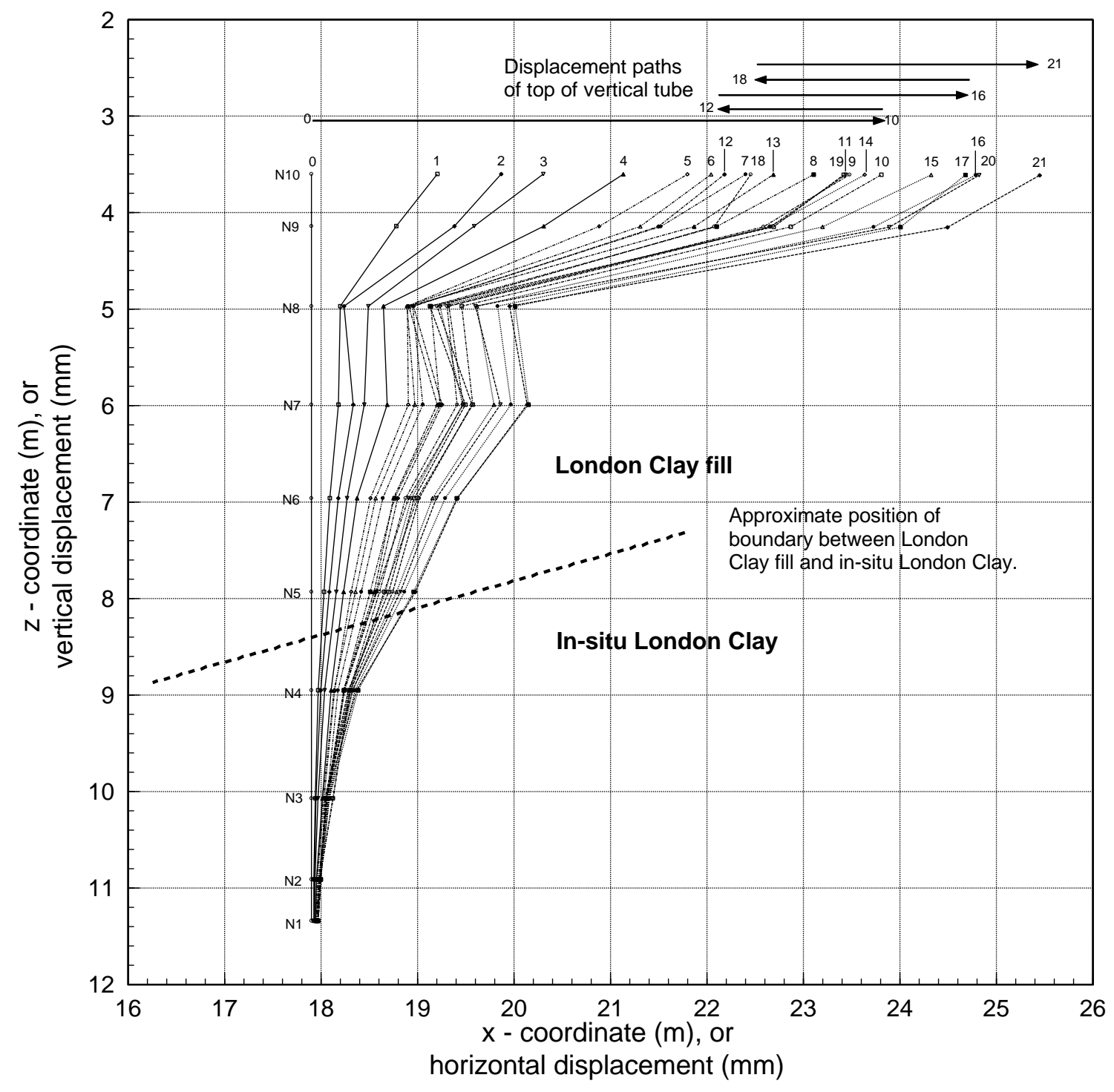

(c)

Figure 9. Processed electrolevel data from High Barnet expressed with dual scale for: (a) horizontal tube (with inset sketch showing assumptions and methodology used in determining displacements from electrolevel rotations); (b) raking tube; (c) vertical tube; and (d) summary plot. Note that values at ends of each profiles relate to week numbers. 


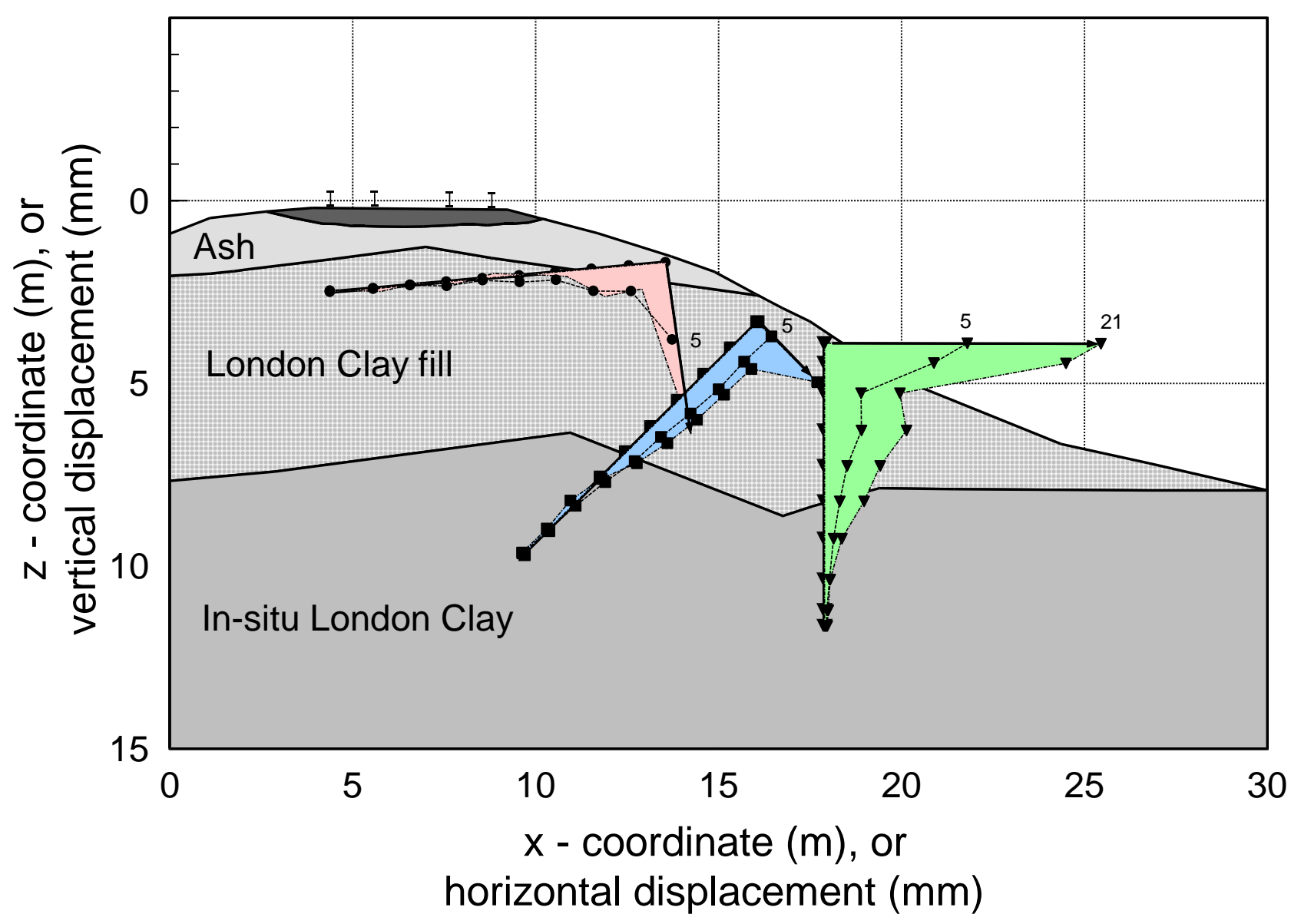

(d)

Figure 9. Processed electrolevel data from High Barnet expressed with dual scale for: (a) horizontal tube (with inset sketch showing assumptions and methodology used in determining displacements from electrolevel rotations); (b) raking tube; (c) vertical tube; and (d) summary plot. Note that values at ends of each profiles relate to week numbers. 
(a)

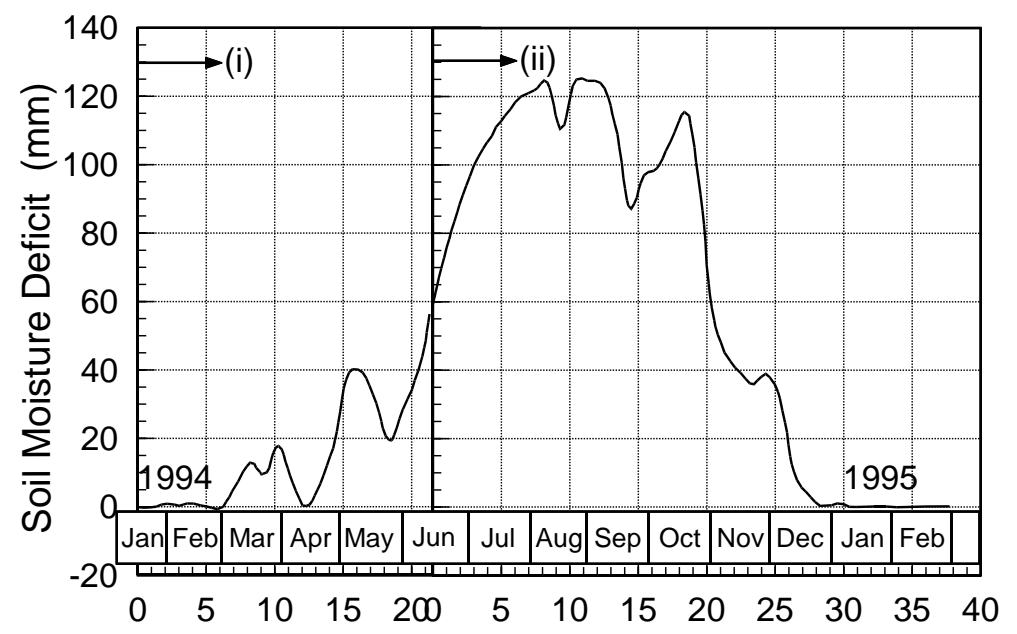

Time (weeks relating to (i) High Barnet, (ii) Roding Valley)

(b)
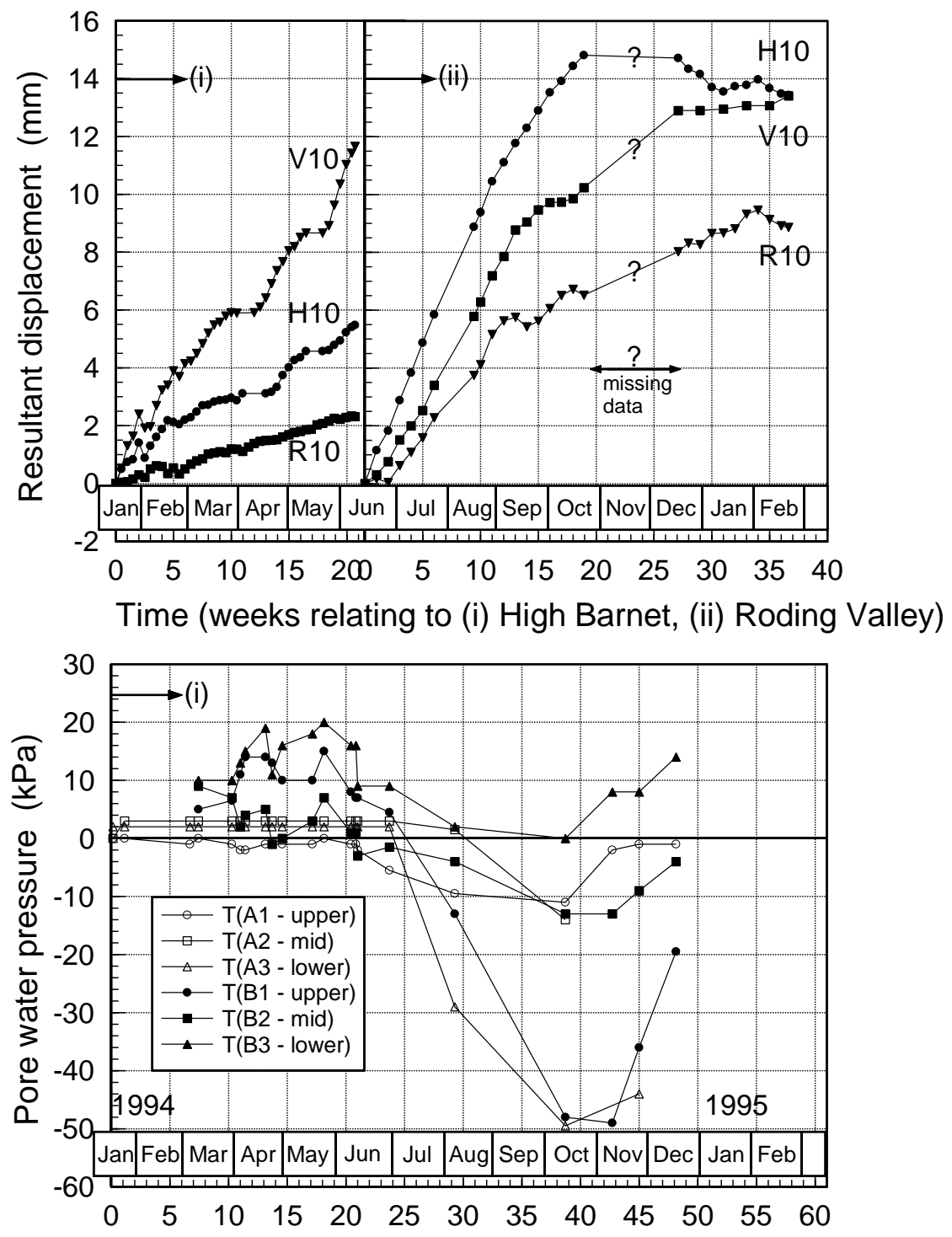

Time (weeks from 16.01.1994, relating to (i) High Barnet)

Figure 10. Relation of displacements and pore water pressures with SMD plotted against entire duration of monitoring at High Barnet and Roding Valley: (a) SMD; (b) progressive development of displacement of upper most electrolevel tubes (with effects of fettling removed; and (c) pore water pressures from tensiometers at High Barnet. 


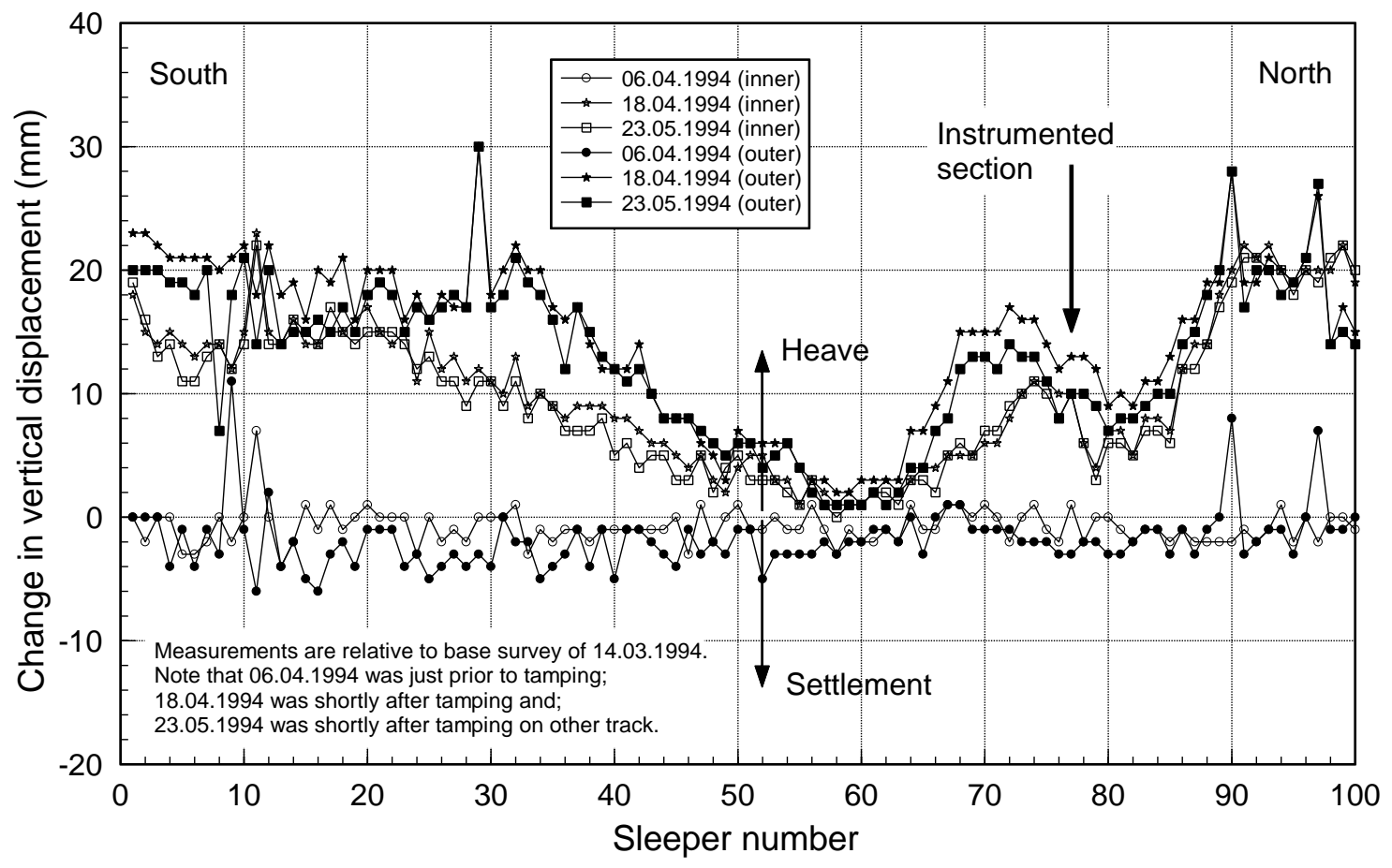

Figure 11. Levelling survey data: effect of fettling works on sleeper levels (inner and outer) at High Barnet. 
(a)
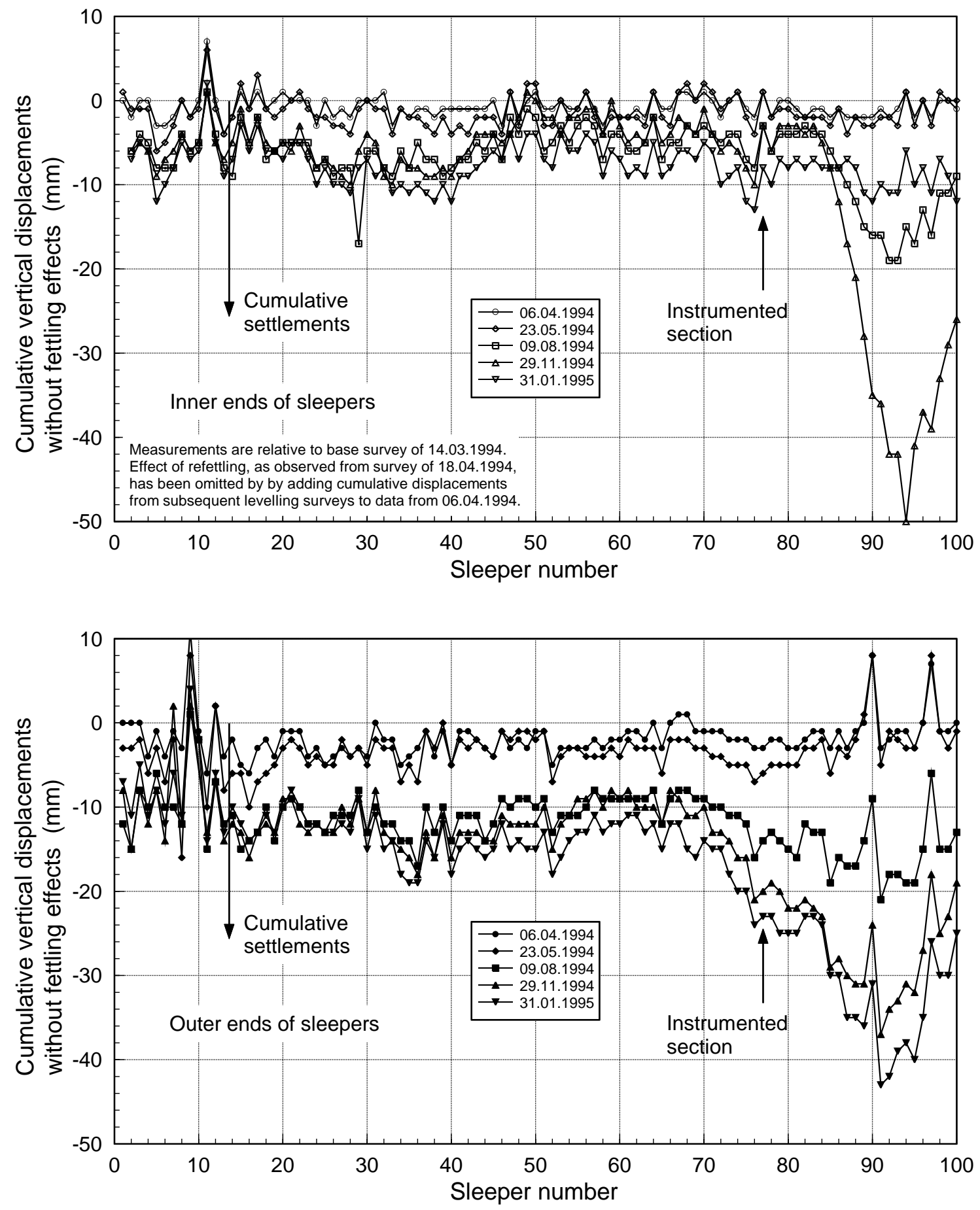

(b)

Figure 12. Levelling survey data: cumulative settlements (with fettling effects removed) over a tenmonth period at High Barnet: (a) inner; (b) outer sleeper ends. 


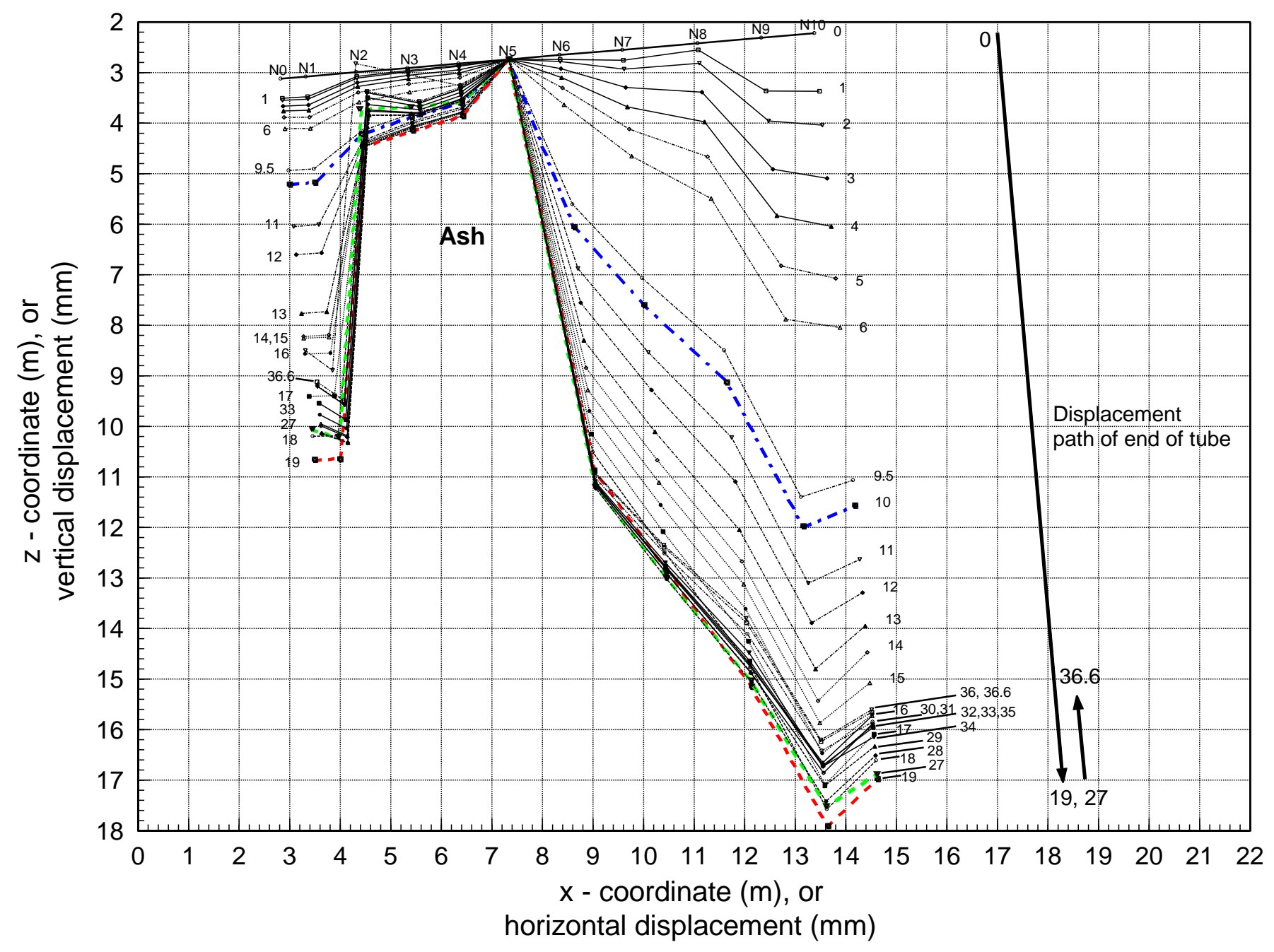

(a)

Figure 13. Processed electrolevel data from Roding Valley expressed with dual scale for: (a) horizontal tube; (b) raking tube; (c) vertical tube; and (d) summary plot. Note that values at ends of each profiles relate to week numbers. 


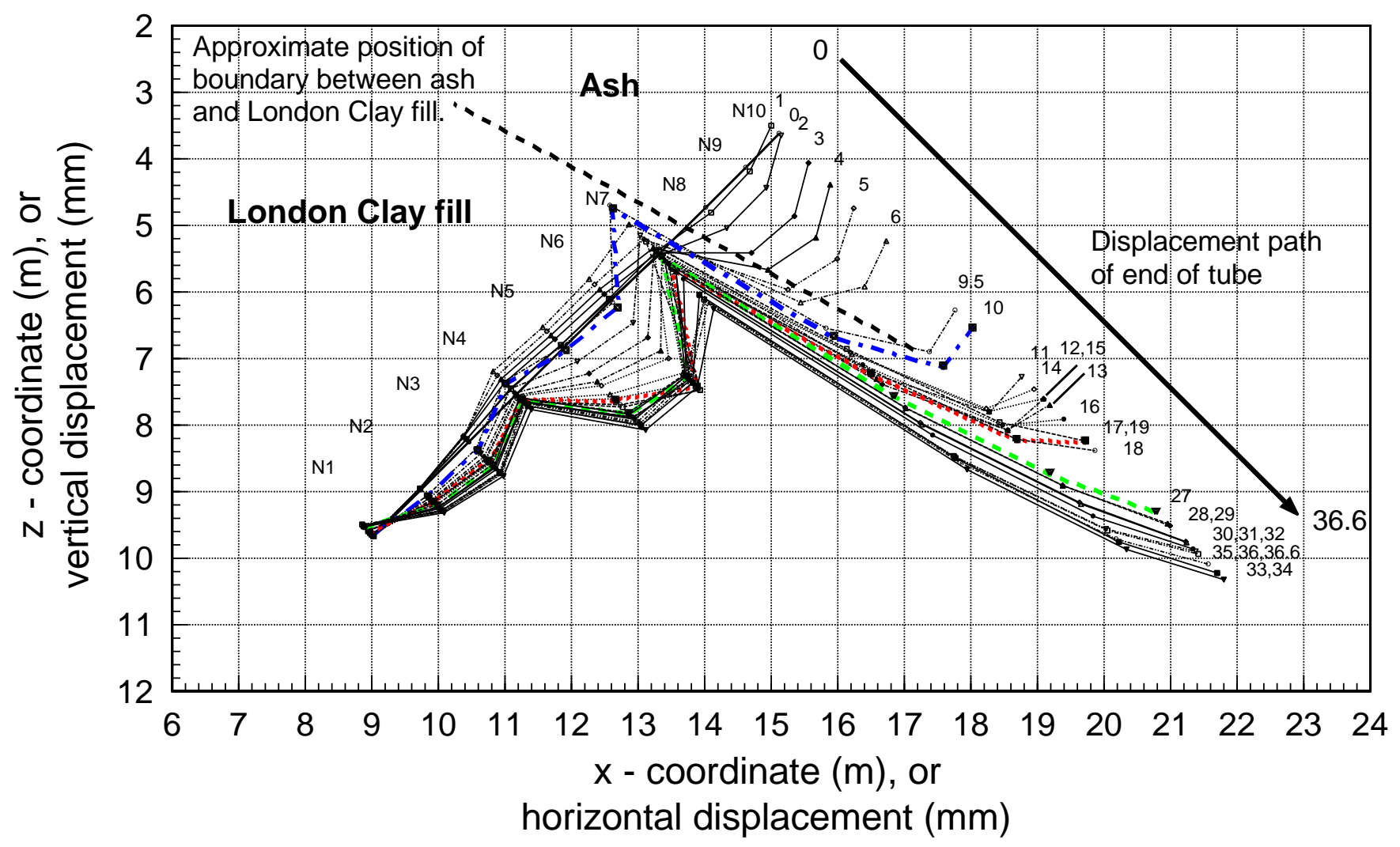

(b)

Figure 13. Processed electrolevel data from Roding Valley expressed with dual scale for: (a) horizontal tube; (b) raking tube; (c) vertical tube; and (d) summary plot. Note that values at ends of each profiles relate to week numbers. 


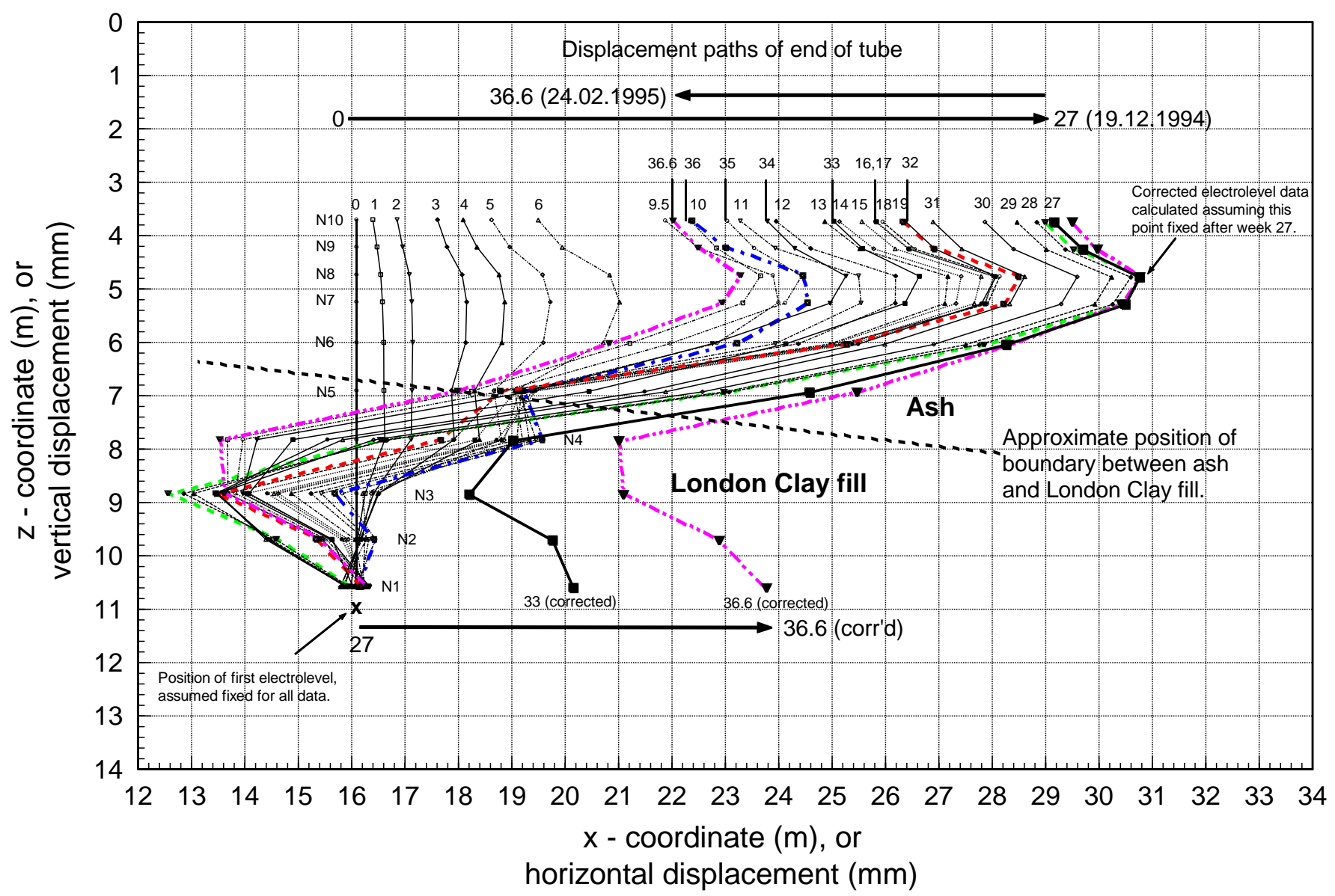

(c)

Figure 13. Processed electrolevel data from Roding Valley expressed with dual scale for: (a) horizontal tube; (b) raking tube; (c) vertical tube; and (d) summary plot. Note that values at ends of each profiles relate to week numbers. 


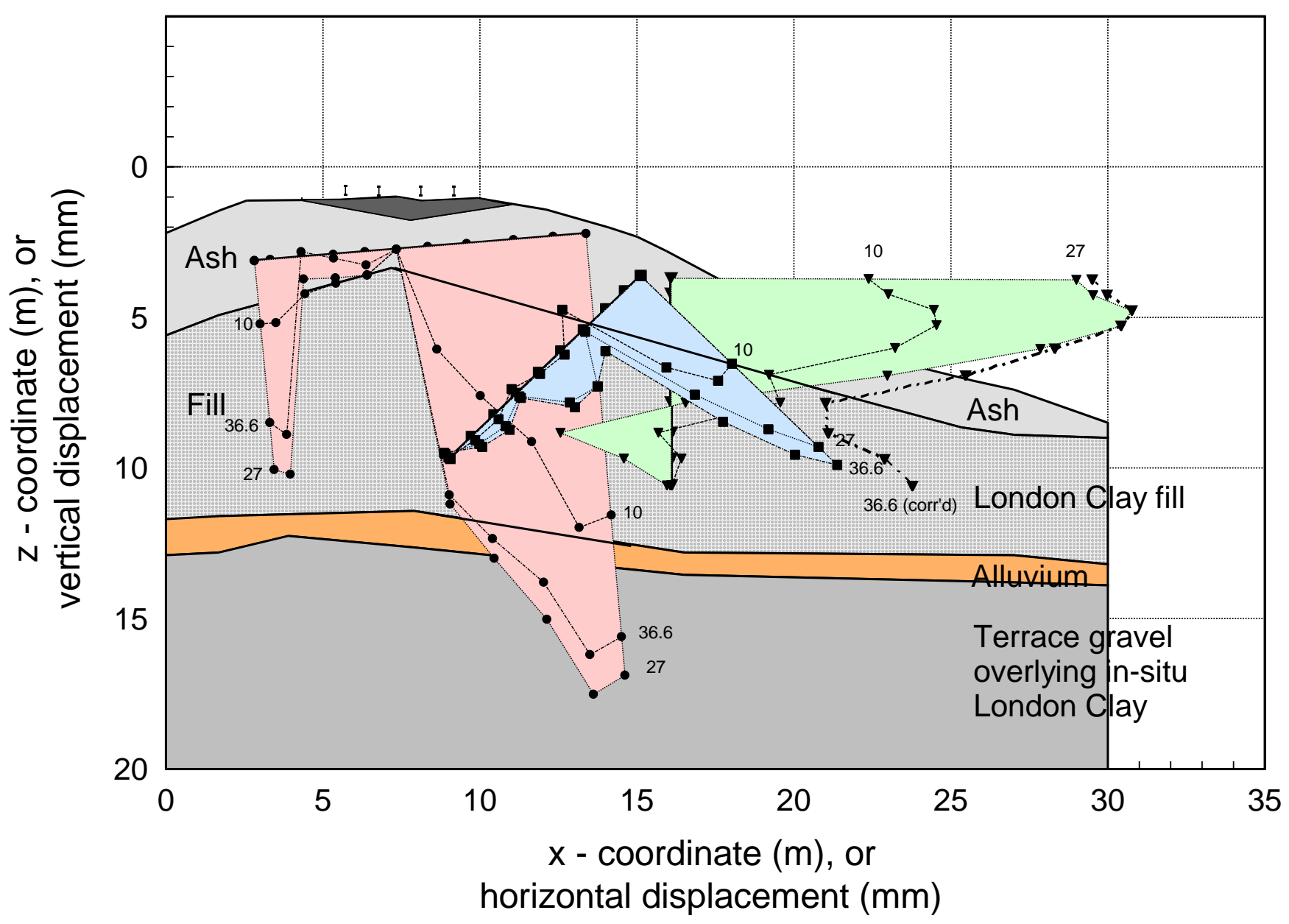

(d)

Figure 13. Processed electrolevel data from Roding Valley expressed with dual scale for: (a) horizontal tube; (b) raking tube; (c) vertical tube; and (d) summary plot. Note that values at ends of each profiles relate to week numbers. 


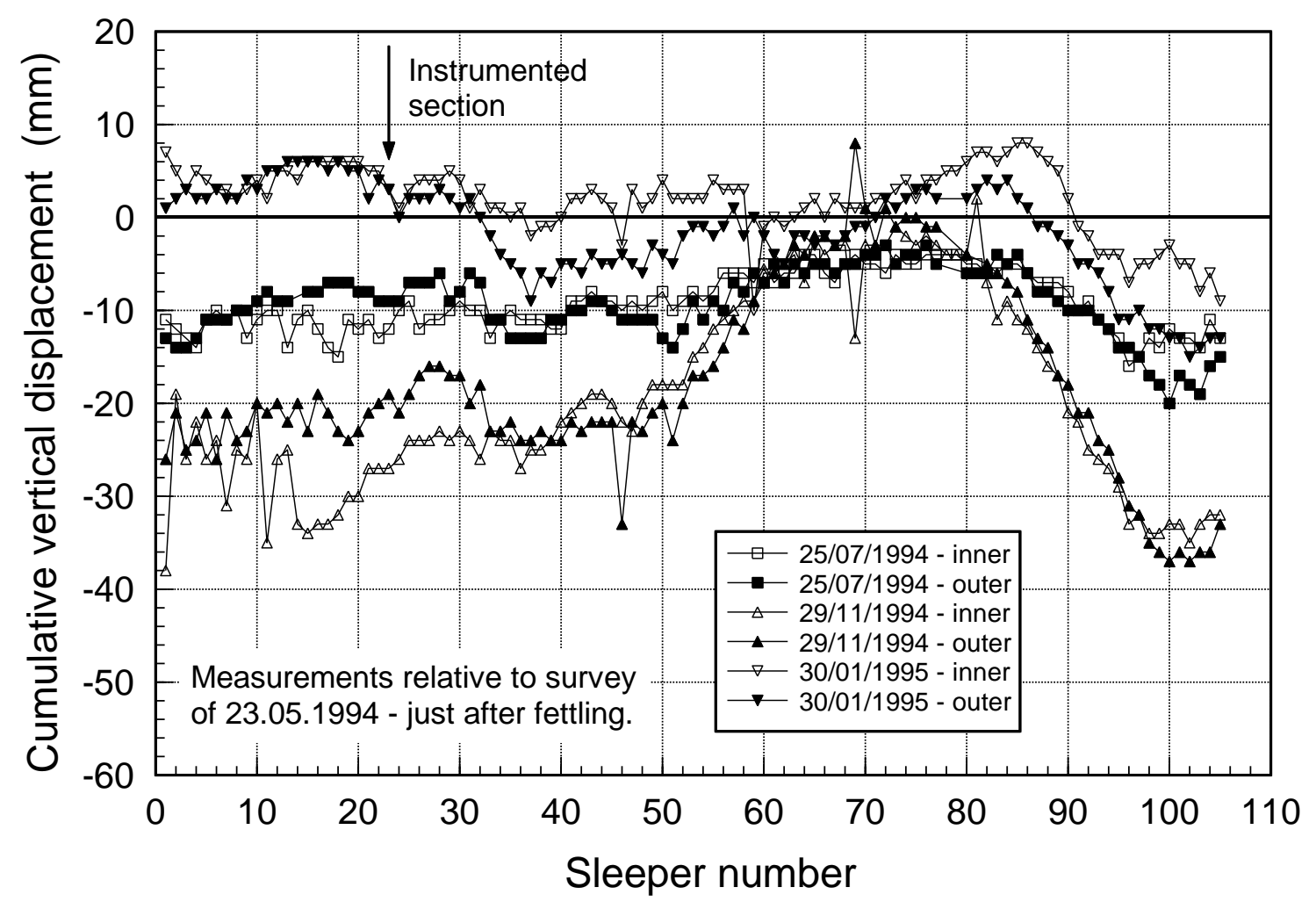

Figure 14. Track levelling survey data: cumulative settlements over an eight-month period at Roding Valley. 


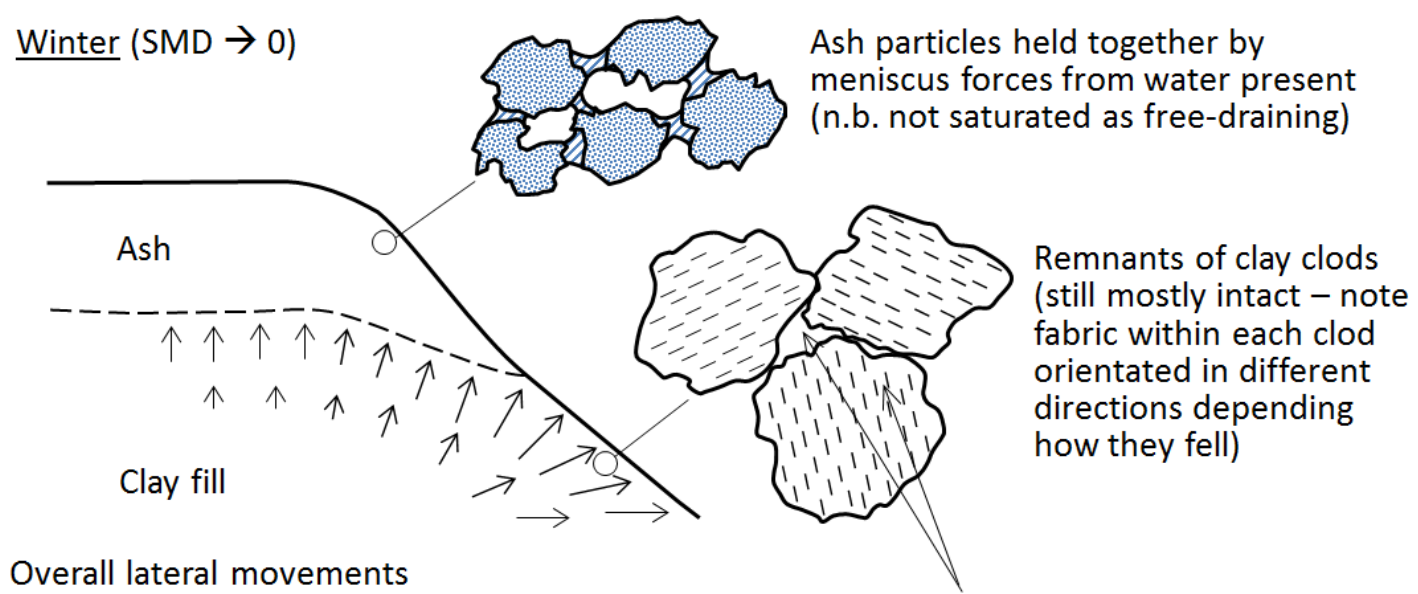

are larger than vertical because of overburden (and Clay clods slightly swollen from water present. Spaces between clods filled with wet softened clay (from preakdown of outer surface of clods) or water.

(a)

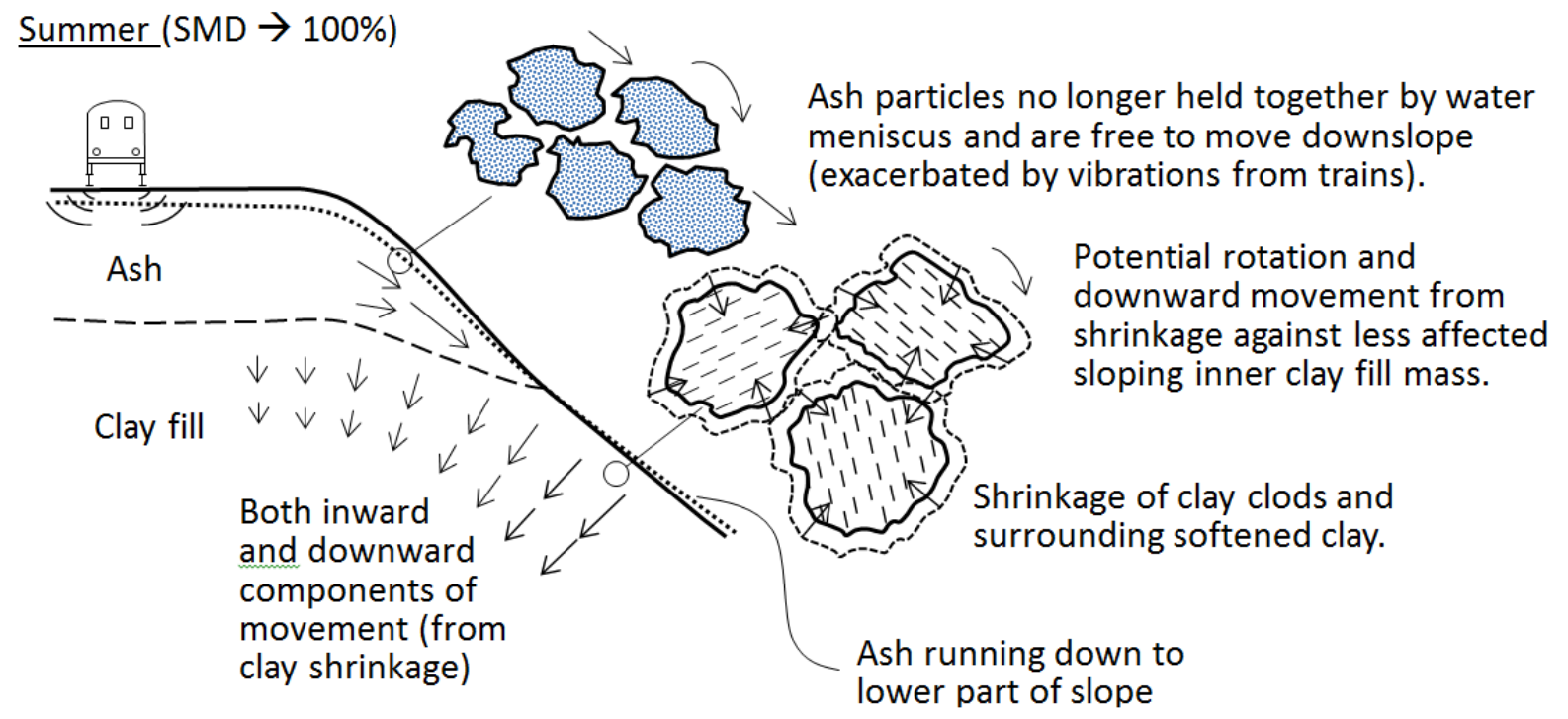

(b)

Figure 15. Schematics showing mechanisms of seasonal embankment fill movements for: (a) Winter; and (b) Summer conditions. 


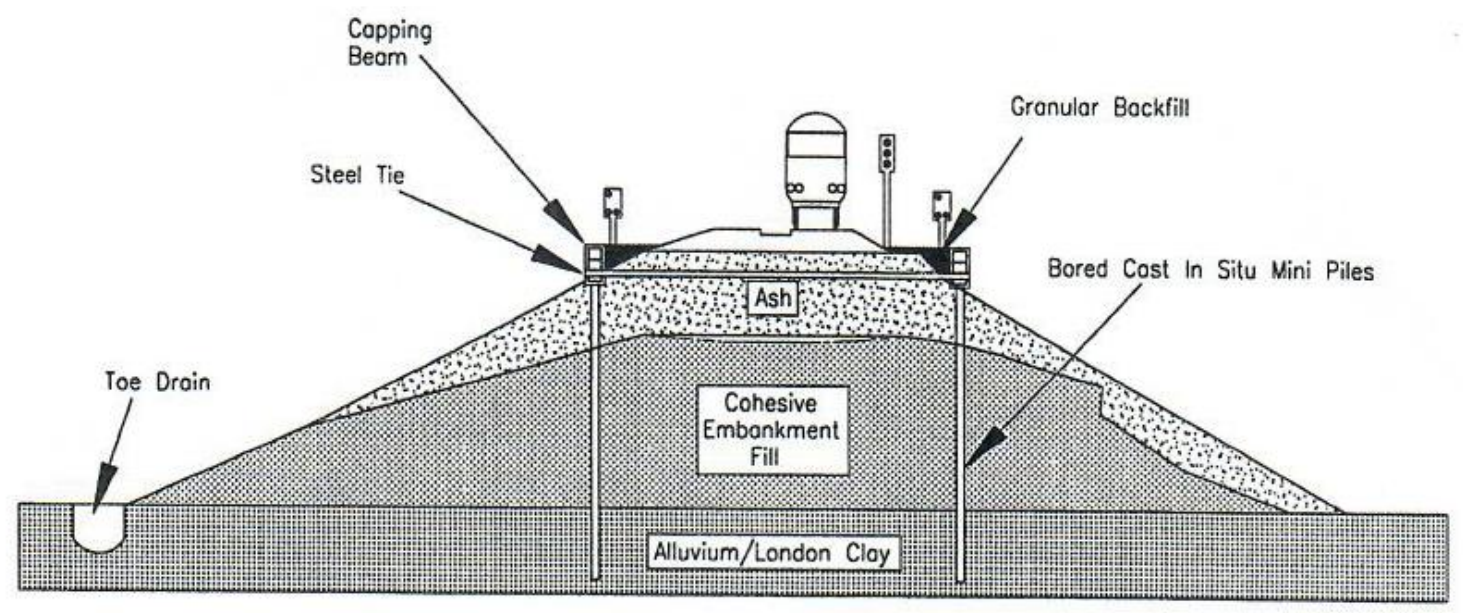

(a)

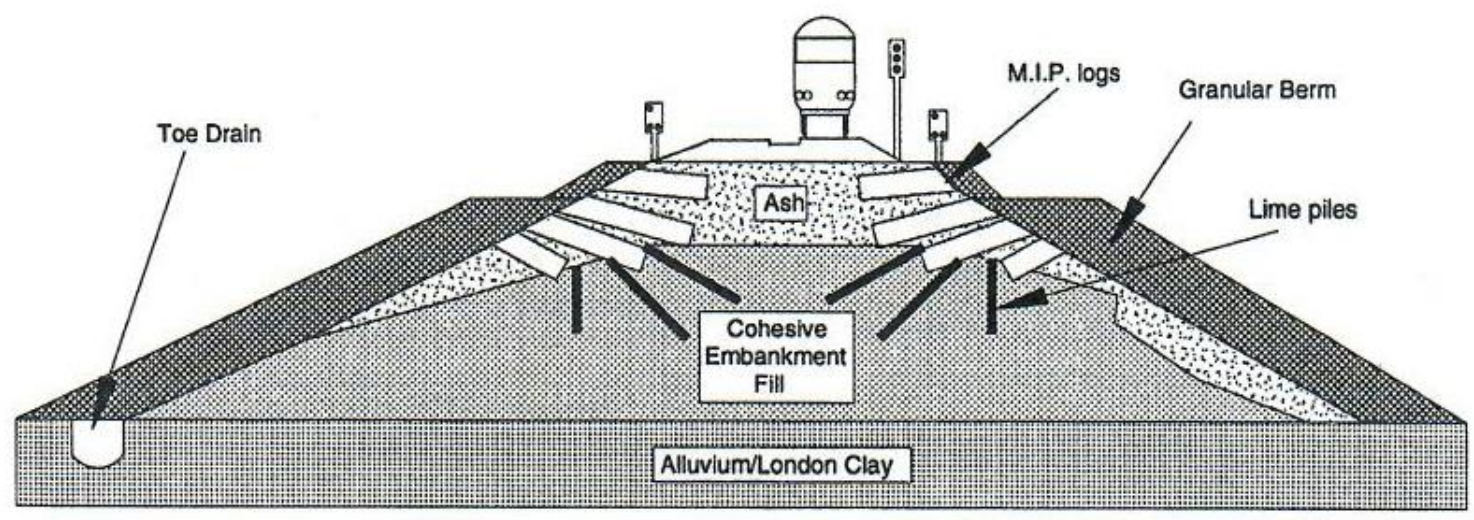

(b)

Figure 16. Stabilisation methods for the ash/clay fill embankments: (a) tied bored mini pile walls; (b) mixed-in-place (MIP) logs and lime piles (from McGinnity et al., 1998). 